\title{
Recycling Behaviour of Italian Citizens in Connection with the Clarity of On-Pack Labels. A Bottom-Up Survey
}

\author{
Farzaneh Amir Kavei * and Laura Savoldi *(D) \\ Dipartimento Energia "Galileo Ferraris", Politecnico di Torino, 10129 Torino, Italy \\ * Correspondence: farzaneh.amirkavei@polito.it (F.A.K.); laura.savoldi@polito.it (L.S.); \\ Tel.: +39-0110904559 (F.A.K.); +39-0110904559 (L.S.)
}

check for updates

Citation: Amir Kavei, F.; Savoldi, L. Recycling Behaviour of Italian Citizens in Connection with the Clarity of On-Pack Labels. A Bottom-Up Survey. Sustainability 2021, 13, 10846. https://doi.org/10.3390/ su131910846

Academic Editor: Isabella Pecorini

Received: 26 May 2021

Accepted: 22 September 2021

Published: 29 September 2021

Publisher's Note: MDPI stays neutral with regard to jurisdictional claims in published maps and institutional affiliations.

Copyright: (c) 2021 by the authors. Licensee MDPI, Basel, Switzerland. This article is an open access article distributed under the terms and conditions of the Creative Commons Attribution (CC BY) license (https:// creativecommons.org/licenses/by/ $4.0 /)$.

\begin{abstract}
The present work studies, through an online survey, the recycling behaviours of a representative sample of Italian end users, in connection with the effectiveness of on-pack recycling indications of different packed materials. The study has a special focus on the clarity of on-pack recycling indications to convey waste sorting information, and the impact of clear and straightforward labelling to improve the sorting result. The work took advantage of social media as the distribution platform, thus obtaining a relatively high involvement of citizens. To investigate the representativeness of the sample, some of its characteristics were subject to checks and comparisons to their corresponding values of the Italian population. According to almost three-quarters of the responders, a clear and straightforward labelling will improve the result of their waste sorting drastically. The general awareness of the answerers relative to the importance of waste recycling and willingness to improve the quality of their sorted waste is very high among the participants but the overall satisfaction of the on-pack indications is relatively low. The score of on-pack labels in conveying information on recycling and waste segregation is evaluated as improvable. A higher perception of circular economy concept leads to more re-utilisation of the packaging parts, which increases with the awareness about the importance of recycling.
\end{abstract}

Keywords: recycling behaviours; on-pack recycling labels efficiency; recycling labelling; circular economy; online bottom-up survey; Italian case study

\section{Introduction}

Waste management is a global issue which with the universal increasing trend of consumption, urbanisation and population growth is expected to worsen in the coming years [1]. In 2019, the global market of waste management has accounted for 2080 billion US dollars and is forecasted to increase even further [2,3]. Waste management has become more complicated after China's waste import ban initiative [4]. For decades, China has been the most important importer of recyclable waste [4,5] and the main trade partner of EU for plastic waste [5], but in 2017 the country announced its new strategy to ban the import of some classes of waste including plastic, paper, and metal. This change has forced the world, especially Europe, to develop new intra and extra-EU waste destinations and markets [5] and adapt new measures and management programs. Note that 35.4\% of $492 \mathrm{~kg}$ per capita of Municipal Solid Waste generated in Europe in 2018 was composed by packaging waste (see the horizontal lines in Figure 1). Italy together with Germany, Luxemburg, Ireland, and France had packaging waste per capita higher than the European mean value [6].

Reuse and recycling of wastes as a sustainable way of material management, besides having a rather immediate effect on reducing the environmental impacts of growing global consumerism, provide additional resources and reduce the dependency on raw materials [7]. Despite a consolidated and strong legal waste management framework, according to the European Commission, in some EU countries just $20 \%$ of domestic waste 
is recycled [8]. In EU-27 countries, less than half of the municipal solid waste is treated in a sustainable way ( $30 \%$ recycled and $17 \%$ composted). Incineration and landfilling with $51 \%$ still form the prevalent waste treatment methods [8]. To tackle this problem, the EU endorses the adoption of different pro-environmental frameworks [9] such as new Circular Economy Action Plan (CEAP) [10] or EU's Directive on packaging and packaging waste [11] taking advantage of the so-called five-stage waste hierarchy which promotes the prevention of waste generation, preparation of the reutilisation and recycling as the Europe's three first priorities [12]. Scientists and companies have also begun to discuss and introduce innovative solutions to reduce material use and enhance sustainability and recyclability of the packaging [13,14]. Meanwhile, the awareness of the consumers on environmental impacts of packaging has increased [15-17] in such a way that they are even ready to pay more for eco-friendly products $[18,19]$.

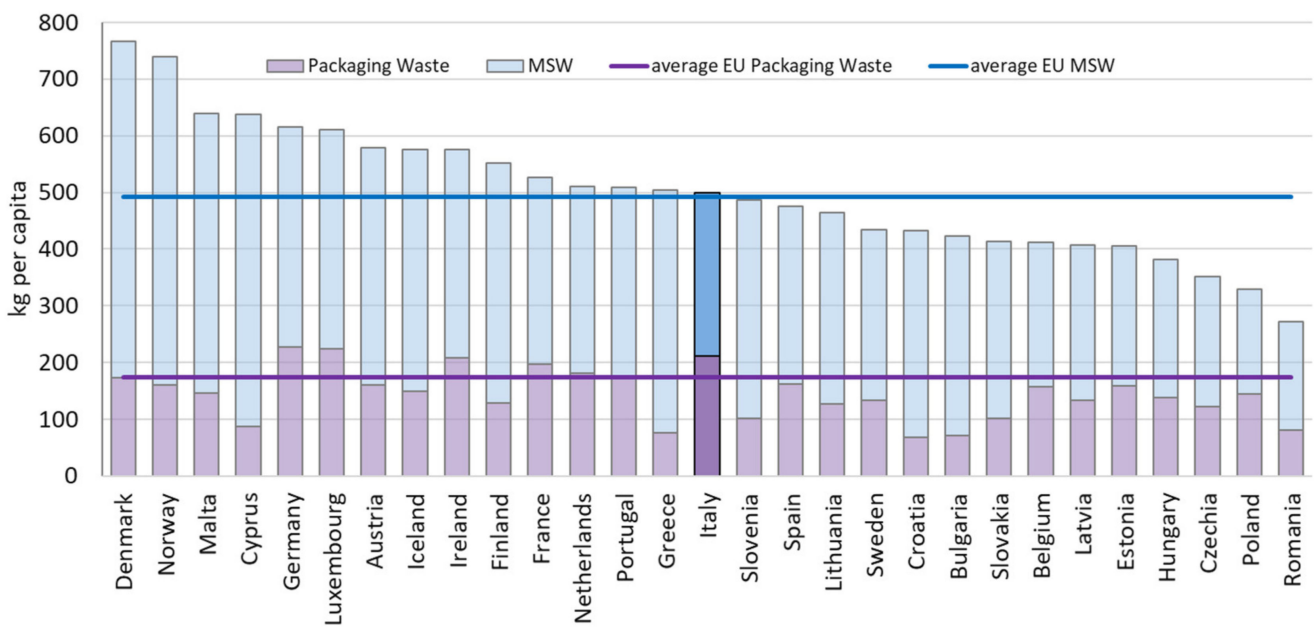

Figure 1. Municipal Solid Waste and Packaging Waste in $\mathrm{kg}$ per capita generated in some European countries and the European average in 2018-elaboration of Eurostat data.

Packaging in general, and food packaging specifically, is an indispensable part of the products and varies based on the nature of the goods and in different steps of the supply chain. It provides containment, preservation, protection, identification [20], and at the same time reduces the (food) waste [13,21]. Food packaging attributes can be divided into physical or non-physical [22] and include structural, graphical, and verbal designing factors [23] to communicate with the consumers in different ways, influencing their perception of the quality, usability, attractiveness, and willingness to buy [24,25]. According to Plumb et al. [26], packaging loses its precepted value as soon as the product reaches its final destination turning into waste. In this phase, some other attributes-such as "cleaning ease", "emptying ease", or "separation into different fractions ease" - start working and influence positively or negatively the decision and behaviour of the final user relative to sorting and recycling [22,27-29].

Waste sorting can occur either at material recovery facilities or wherever the waste is generated (source separation [29]). Whilst the former demands specific machinery and requires technical and manual works, performing a proper source separation is behaviourbased and relies on involvement of citizens and adequate recycling services [28].Yet, packaging materials are a challenging issue for the actual recycling systems and a considerable part of them cannot be recycled in a sustainable way $[13,23]$. One of the principal reasons of uncertainty about the recyclability of the packaging is the lack of information on that which results in the confusion of the consumers [29]. A more perceptible information present on the packaging could be a strong driver to perform recycling [30]. In the literature numerous works assess different information present on the packaging. The effect of front-pack nutrition labels on consumers' behaviours are investigated in [31-34]. Some studies examine the effect of packaging attributes (such as shape, colour, size) on recycling behaviours of the 
end users $[23,30]$, while some others examine the same factors together with the recycling information on the packages [23].

As the recycling labels are planned to transmit a predefined concept, i.e., the sorting method and material category the package belongs to, they have a more standard representation independently from other above-mentioned attributes and consequently are easier to evaluate in a holistic approach. A clear and straightforward recycling infographic is the first and the most important information source for a citizen, willing and ready to perform a correct and efficient waste sorting. This work aims at the evaluation of the impact of on-pack recycling indications on the recycling behaviour of the final users with reference to their awareness of the importance of recycling and circular economy. The evaluation is based on the results of an online survey targeted to Italian citizens. Unlike the survey done by Nemat et al. [22] in which the main source of getting recycling indications are "sources other than package", in our study the focus is devoted to "on-pack indications" as the main source of a correct sorting and recycling. The results of the survey could help in understanding how functional the existing recycling-related indications are, relying on the evaluation of the final users.

The paper is structured as follows: first, the methodology of the survey and its questions are introduced. Then, the sample and its main characteristics such as age and gender of the participants are presented, followed by the discussion of the composition and representativeness of the sample. The analysis of the main survey outcomes is presented in Section 3, while the conclusions are recommendations follow in Section 4. Finally, in Appendix A, the survey is reported, and the corresponding raw data are available in Appendix B.

\section{Methodology}

Different directives in line with the European policies regulate the Italian national strategy of waste and packaging waste management [35,36], which form a non-negligible share of Italy's MSW (see Figure 1). In 2018, 13.3 million tonnes of packaging material were released for consumption in the national Italian market, which was $0.8 \%$ more than in 2017 [37]. The recycling system in Italy is managed by municipalities and spans from doorto-door to kerbside collection or a mix of both. The sorting categories include "plastic", "paper and paperboard", "metal and glass", "organic", and "non-recyclable waste".

The very first and crucial point to effective source waste separation is inside the dwellings, and it is important to monitor how functional the tools at this level are. This can be done by means of a survey targeting the end users. The first idea was to perform a normal paper-based survey, but the pandemic makes the individual contacts, distribution, and collection of the questionnaires if not impossible, highly complicated and unsafe. Therefore, a digital format was preferred.

The survey was developed using the commercial LimeSurvey online tool (www. limesutvey.net, accessed on 30 March 2021), in which different predefined templates can be set together to form a complete survey. In the free version, the first 25 answers are stored free of charge, but to increase the storage space, users can upgrade the free version buying their preferred plan among the solutions on the website.

The link to the survey has been circulated between end of March and end of April 2021 in Italy. The choice of the survey's language was based on the targeted society (using the native tongue of the authors and potential participants). To expand the categories of participants, instead of sending the survey link via email to mailing lists (accessible for instance through university database), social platforms such as WhatsApp (mainly), digital newsletters of two associations "Cochlear Implant Careers Association-APIC" [38] and "FIAB Torino, Bici \& Dintorni", a biking society [39], and word-of-mouth method were adopted.

The disadvantage of the digital questionnaire, if compared to a paper-based one or interviews, is that, in the case of interviews or paper-based surveys, it is possible to explain the unclear points, in case participants feel confused and require more description about 
some questions. Moreover, online surveys (as well as paper-based ones) may include incomplete modules, while in an interview all answers are gathered by interviewers and thus tend to be complete. However, the online choice shows two clear advantages:

- Participants can choose to enter the survey more freely than interview or the paperbased surveys;

- The answers will be more real when there is no need to save face in front of interviewer.

The initial page of the survey, containing the survey's link, provided a short introduction to the survey and its goals. The survey was managed in such a way as to be completable in different access times in case some answerers needed to finish it in different phases/time steps. Moreover, the survey was organised to prevent duplicate participations (after reaching the last page of the survey, saving, and sending the completed module, the same IP was not allowed to access a new blank questionnaire).

All questions had predefined answers. In some cases, such as city of residence, the participants could enter their city's name in a text box. In some other cases (and if the present answers did not include the desired answer of the participant) the answerers could add additional explanations to their answers by choosing the option other.

The survey (see Appendix A for original web format and Appendix B for English version and statistics) gathered 572 answers ( 452 complete answers and 120 partial) from more than 90 Italian cities. (As the insertion of the exact name of the city was optional, the reported number covers the inserted cases, while the exact number may exceed 90 cities.) As it was possible to leave the survey at every step of completion, some surveys were incomplete. We extended the analysed sample to all the modules which reached at least $67 \%$ of completion (i.e., 12 question pages over 18). This choice has resulted in relatively higher frequency of blank answers (denoted by N.G.) in case of questions situated in the final pages of the survey (see Appendix B).

The survey's questions (see Table 1) can be divided into four main categories based on their topic: general questions which address age range, study level, residential context and the percentage of the packed products consumed weekly; questions related to recycling habit; questions which examine the environmental knowledge and sensitivity of the participants, and questions which were targeted to score the quality of on-pack indications of different packaging materials (Q15-Q21 in Table 1) or product typologies (Q24-Q27 in Table 1). For the product typology, we have chosen cosmetics, because so far and to our knowledge, only their eco-design has obtained attention [40], and ready meals, because the change of lifestyles has led people to use more ready meals in the recent years. The column on the left of Table 1 indicates the type of the answers and are namely $\mathbf{R}$ for the answers containing Ranges, $\mathbf{D}$ for the answers Describing a situation or quality, and $\mathbf{S}$ for the answers where participants chose a Score in a (1-10) scale. Note that the available templates on the LimeSurvey include the (1-5) or (1-10) scoring arrays. Since the (1-10) arrays give a wider range for the participant to score, they were adopted in the survey.

Aa it was mentioned before, all questions had predefined answers and in the case of some descriptive questions (e.g., relative to recycling habits and environmental knowledge) and where the plausible answers seemed to be numerous, we added the option "other" in which participants could add their own comments in a text box. In the questionnaire, there was a conditional question (Q9 in Table 1), in which the participants were asked about the importance they give to waste sorting. If the selected answer was "I don't do it", another question would have appeared to ask the reason for that (see Appendix B, Tables A6 and A8). 
Table 1. List of the main survey questions, translated in English—survey in the original language (Italian) and format is available in Appendix A; translated questions and answers and the statistics in Appendix B.

\begin{tabular}{|c|c|}
\hline General Questions & Type \\
\hline Q1-Age & $\mathrm{R}$ \\
\hline Q2-Gender & $\mathrm{D}$ \\
\hline Q3-Residence urban context and city name (with insertion of city name) & $\mathrm{D}$ \\
\hline Q4-Study situation/level & $\mathrm{D}$ \\
\hline \multicolumn{2}{|l|}{ Recycling Habits } \\
\hline Q5-Estimated percentage of packed products consumed weekly & $\mathrm{R}$ \\
\hline Q6-Quality of the waste sorted at your home & $\mathrm{D}$ \\
\hline $\begin{array}{l}\text { Q7-Reason why you do not sort the waste (appeared if the answer to the conditional } \\
\text { question was "not performing waste sorting") }\end{array}$ & $\mathrm{D}$ \\
\hline Q8-Impact of clear and simple labelling on your recycling habits & $\mathrm{D}$ \\
\hline \multicolumn{2}{|l|}{ Environmental Sensitivity } \\
\hline Q9-Importance you give to recycling and waste sorting (conditional question) & $\mathrm{D}$ \\
\hline Q10-Habit to reuse some parts of packaging & $\mathrm{D}$ \\
\hline Q11-Knowledge about why it is important to recycle and sort waste & S \\
\hline Q12-Knowledge about circular economy & S \\
\hline Q13-Quality of on-pack sorting and recycling indications & S \\
\hline Q14-Information conveyed by media about the correct ways of waste sorting & S \\
\hline \multicolumn{2}{|l|}{ Targeted Questions } \\
\hline Q15-On-pack sorting and recycling indications of Atmospheric Pressure Plastic packaging & S \\
\hline Q16-On-pack sorting and recycling indications of vacuum packaging & S \\
\hline Q17-On-pack sorting and recycling indications of paper packaging & $\mathrm{S}$ \\
\hline Q18-On-pack sorting and recycling indications of wood packaging & S \\
\hline Q19-On-pack sorting and recycling indications of metal packaging & S \\
\hline Q20-On-pack sorting and recycling indications of glass pack packaging & S \\
\hline Q21-On-pack sorting and recycling indications of tetra pack packaging & S \\
\hline Q22-Current on-pack indications of single-component packaging & $\mathrm{S}$ \\
\hline Q23 - Current on-pack indications of multi-component packaging & S \\
\hline Q24-The presence of the on-pack recycling indications of ready meals & S \\
\hline Q25-The presence of the on-pack recycling indications of cosmetics & S \\
\hline Q26-The clarity of the on-pack recycling indications of ready meals & S \\
\hline Q27-The clarity of the on-pack recycling indications of cosmetics & $S$ \\
\hline Q28-Availability of the recycle bins in the vicinity of your residence & $\mathrm{D}$ \\
\hline
\end{tabular}

\section{Results and Discussion}

In this section, some verifications performed on the sample to evaluate its representativeness are presented, followed by the analysis and discussion of the results of the survey. In some cases, the $\mathbf{D}$ or $\mathbf{S}$ questions (see Section 2. Methodology) are analysed individually and in some cases, questions of both types are analysed together to obtain a better understanding of different aspects of a topic.

\subsection{Socio-Demographic Representativeness of the Sample}

As participation in the survey was open and the survey had no exclusion criteria other than prevention of duplicate completion, people without any exclusion (for, e.g., age), could have participated in it. Thus, the representativeness of the structure of the sample was consequently analysed from different points, which could have affected or biased the outcomes:

(a) Gender structure, to check that the sample includes both sexes. The gender structure of the sample is highly representative of the Italian population (see in Figure 2a the split of the Italian population, and in Figure $2 \mathrm{~b}$ that of the sample). Considering that in 2020 women made up 51\% of the 60 million population of Italy, the small unbalance in higher fraction of the female participants in our sample could be justi- 
fied by a higher on-average sensitivity of women towards environmental topics, as highlighted by Bord at al. [41]. Regardless, the investigation of the males' answers was interesting because it showed that the sensibility about recycling labels is highly spread among men.

(b) Residence context, as it could impact the consumption pattern of packed products since it is normally higher among city residents. The responders were asked to choose their residence context (see Q3, Table 1) between urban, peri-urban, and rural categories (see Figure 3). In 2019, 42.7\% of the Italian population lived in urban zones and the rest $17.3 \%$-in rural areas. The two urban and peri-urban categories of the sample account for more than $80 \%$. In this regard, the sample does not fully represent the Italian population, but it includes a larger share of population who are possibly packed-product consumers (i.e., urban residents).

(c) Age distribution, since a relatively distributed sample through different ages would help to evaluate the perception of different age categories. The age structure for each gender was examined (for females, see Figure $4 a, b$ for males). The only category in both genders without any participant is the one of "less than 15 years old". After the "Fridays for Future" movement, which was very strong in Italy, we were curious to see if young teenagers were willing to participate in the survey, which has not been the case. The age ranges of the sample appeared to be rather equally distributed between two genders. The only two remarkable differences between genders were seen in the categories $15-30$ and 46-50. Whilst there are more male participants in the first range ( $34 \% \mathrm{M}$ vs. $20 \% \mathrm{~F})$, women are more numerous in the second one (33\% F vs. $19 \% \mathrm{M})$. On a side note, the fact that more than $45 \%$ of the female participants are between 31 and 60 of age is a positive point for the survey because it involves females who manage family affairs and consequently are more in contact with the topic of product packaging and recycling.

(d) Estimated share of the packed products consumed weekly, to check to what extent the sample is acknowledgeable in awareness about on-pack labels. Italy is a country with a strong tradition of daily markets. As the quantity of packed products in such markets is relatively low, this would have compromised the precision of the judgment of the answerers about the on-pack indications and reliability of the outcomes. Thus, we investigated the estimated percentage of the packed products consumed weekly by the participants (see Q5, Table 1 ). The verification shows that more than $80 \%$ of participants' shopping contains more than $25 \%$ of packed products and at least half of the weekly shopping of $47 \%$ of participants is in packed format (see Q5, Appendix B for statistics). Only $19 \%$ of the answerers consume less than $25 \%$ packaged products. This allows to conclude that the declaration of the majority of the participants is truly based on their daily experience.

(e) Sensibility towards waste sorting and recycling topics, to verify if the participants are interested in waste sorting at all. The participants were asked about the importance they give to this topic (see Q9, Table 1). The survey's results would be reliable when recycling is important for those who fill the survey, because it requires the examination of the quality of on-pack labels. Of the participants, $80 \%$ answered that they find recycling very crucial and do it as well as possible (see Q9, Appendix B for statistics). Just one percent of the responders declared that they do not sort waste and that was not because of the lack of interest but because of the absence of the recycling service in their zone. On a side note, the inhabitants of that specific zone (the city of Taranto) could have a very high environmental sensibility, because of the high environmental contamination characterising the air and soil in that place [42]. The rest of the answerers are those who find recycling important but do it just for some categories such as paper or plastic. 


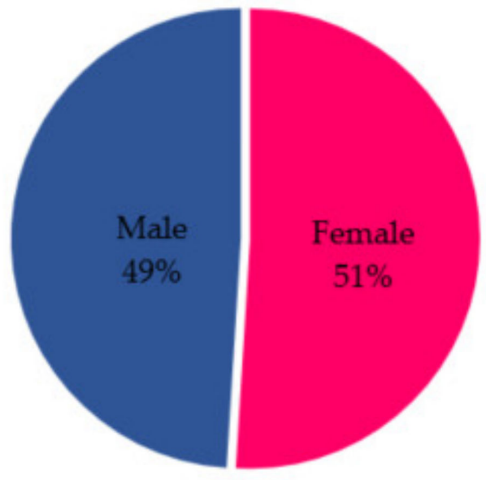

(a)

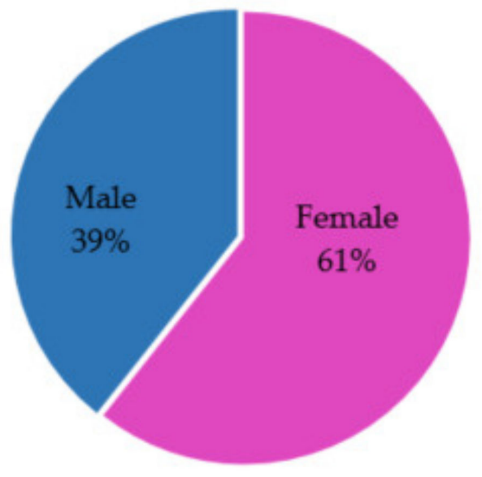

(b)

Figure 2. Gender structure of the (a) Italian population in 2020 and (b) within the survey.

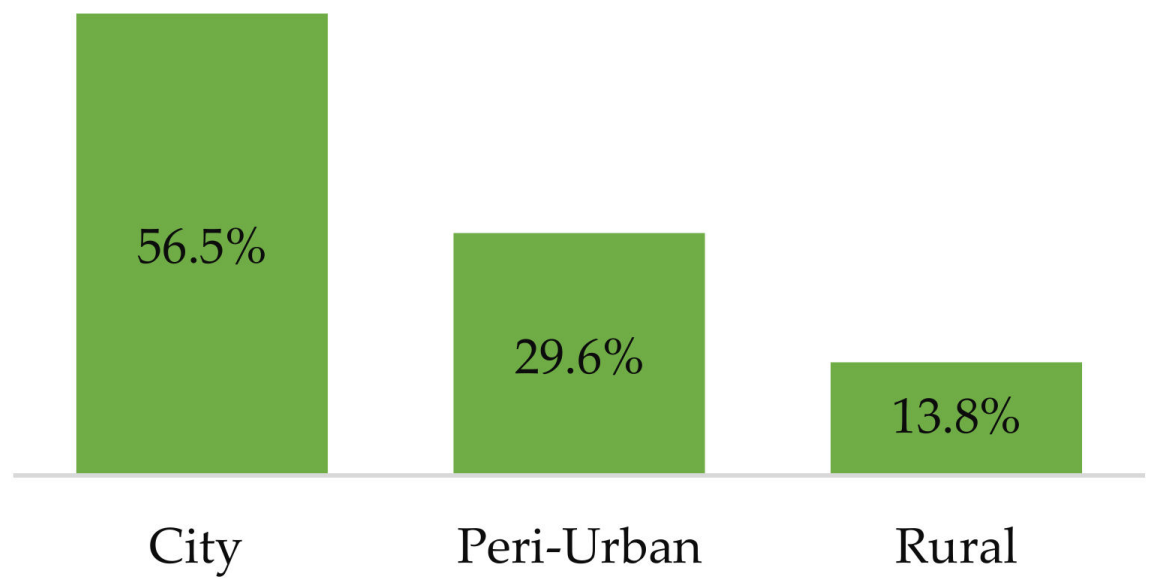

Figure 3. The residence context of sample participants residence.

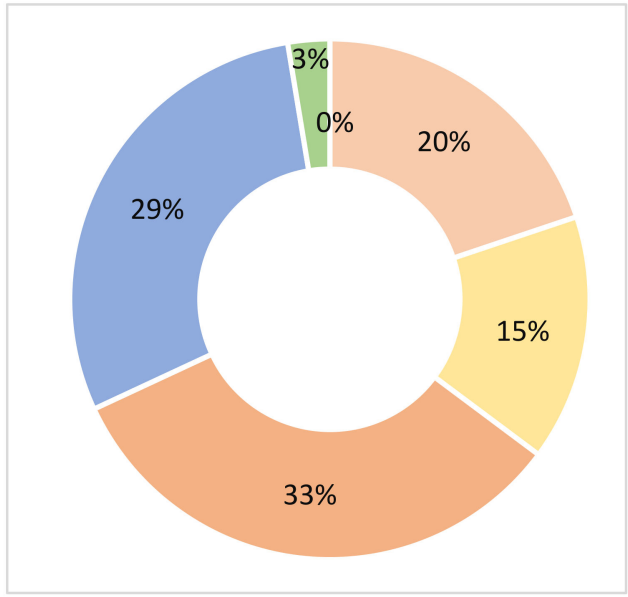

(a)

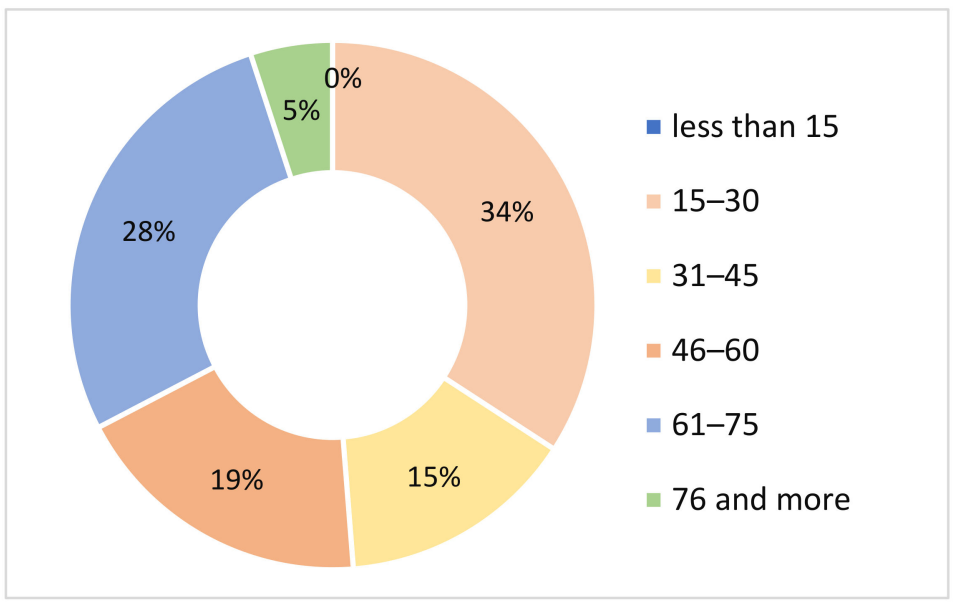

(b)

Figure 4. Age structure of the sample within genders, (a) females and (b) males.

\subsection{Descriptive Questions}

The participants were asked about how a clear and simple recycling label would change their recycling habit (see Q8, Table 1). The answers could be: "it would change dramatically 
because it is the problem", "it will change nothing because they are already clear enough", "it won't change because it is not the problem", and "other". Most of the participants (74\%) had the idea that it would influence dramatically their recycling result. So, we infer that label clarity and simplicity is an issue for the end users. Just $17 \%$ of the participants find the recycling labels clear enough. Choosing "other" gave the possibility to add own comments and 32 participants preferred to add their opinion. Between them, five people expressed again but in different words that having a simple and clear indication is useful to increase or refine the result of recycling. Eight answers hint that having clearer labelling could be helpful for multi-component packaging. Three persons wrote that in case of doubt it would be very useful to have recycling indications to refer to. According to two responders, who have double residence in two different cities, the fact that some wastes are managed differently changing municipality is more confusing than the recycling labels. Finally, two people (one female and one male, both resident in an urban context) indicated that, in case of doubt, they refer to an app to find the recycling category.

To find how the answerers of the question above evaluated the "quality of on-pack recycling labels" (a S question, see Q13, Table 1), we examined the average of the scores of each answer as the indicator of satisfaction of on-pack labels. The average satisfaction in case of those who have chosen "it will change nothing because they are already clear enough", was 7.04 while it was 5.85 for those who felt that "it would change dramatically because it is the problem". The average of the scores in case of "other" was 5.68 while for the "it won't change because it is not the problem" the average value was 5.77. The average of the scores of the first category, though being in an acceptable range, is not high, and it is even lower in the other three cases. Note that only 22 and 29 participants scored the quality of on-pack sorting and recycling indications with 9 and 10, respectively, highlighting that there is a large margin for improvement in that field.

A descriptive question in the survey (see Q6, Table 1) asked the participants to describe the quality of their sorted waste. The participants could choose their answer between: "very high, impossible to improve", "high but improvable", "medium, as good as possible", "perfect for paper", "perfect for plastic", "perfect for glass $\mathcal{E}$ cans", "perfect for plastic", and "other".

The majority of the participants declared their waste's quality as high but improvable, while only $15 \%$ find it to be perfect. Nobody chose plastic as their perfect sorted category and only 3 and 5 answers include a perfect paper and glass $\mathcal{E}$ cans sorted waste. Fourteen people preferred to express their own idea by filling in the available text box. Among them, four people said they cannot find the sorting indications for the right category to be sorted into. For two participants, distinguishing the indications for plastic packaging is an issue and three others have said that the bio-waste is not differentiated in their zone. Two participants complained about not having the support of other family members in waste sorting.

Another question in the survey asked the participants to score their knowledge about the reasons for recycling and sorting waste (see Q11, Table 1). To find out if the quality of segregated wastes (Q6) is related to the awareness about the reason of waste sorting (Q11), we put these two questions in relation. Amongst those declaring their sorted waste as perfect and not more improvable (78 cases), the scores were 5 and above, with 69 cases scoring with $\geq 8$. The scores of the high but improvable category (338 cases) started from 3 and encompass 68 cases with scores between 5 and 7 and only two chose 3 and 4 . High scores have the absolute majority here as well. The conclusion of the analysis of the relation between these two questions is that awareness about the benefits and reasons of waste sorting and the quality of sorted waste are highly related. This point allows diving more deeply in the perception and awareness about the concept of Circular Economy (CE).

In the survey two different questions were dedicated to the CE: an indirect question in which the habit of reutilisation of some parts of packaging was examined without pointing directly to CE (see Q10, Table 1) and the second question, in which the participants were asked directly to score their knowledge about CE (Q12, Table 1). 
The answers to the first question were in descriptive form and could be summarised in: "never", "some parts", "would like but have not enough room", and "other", which like the previous case gave the possibility to enter proper words. From the results reported in Figure 5 one can see that more than $75 \%$ of the responders have the habit to reutilise some packs' parts and those who never reuse are slightly more than $14 \%$. Not having enough space in the dwelling is a reason which hinders reutilisation in almost $8 \%$ of the cases. Furthermore, of those who preferred to express their own opinion by filling the text box, seven people wrote they reuse when they find the pieces useful while one person wrote that she uses the parts as material to make things at school with children. One person stated that they re-use not only packaging parts but also bread bags from bakery. However, no one in this category said they do not have the habit to reuse, therefore, also the 13 people belonging to this category can be considered amongst those who do reuse.

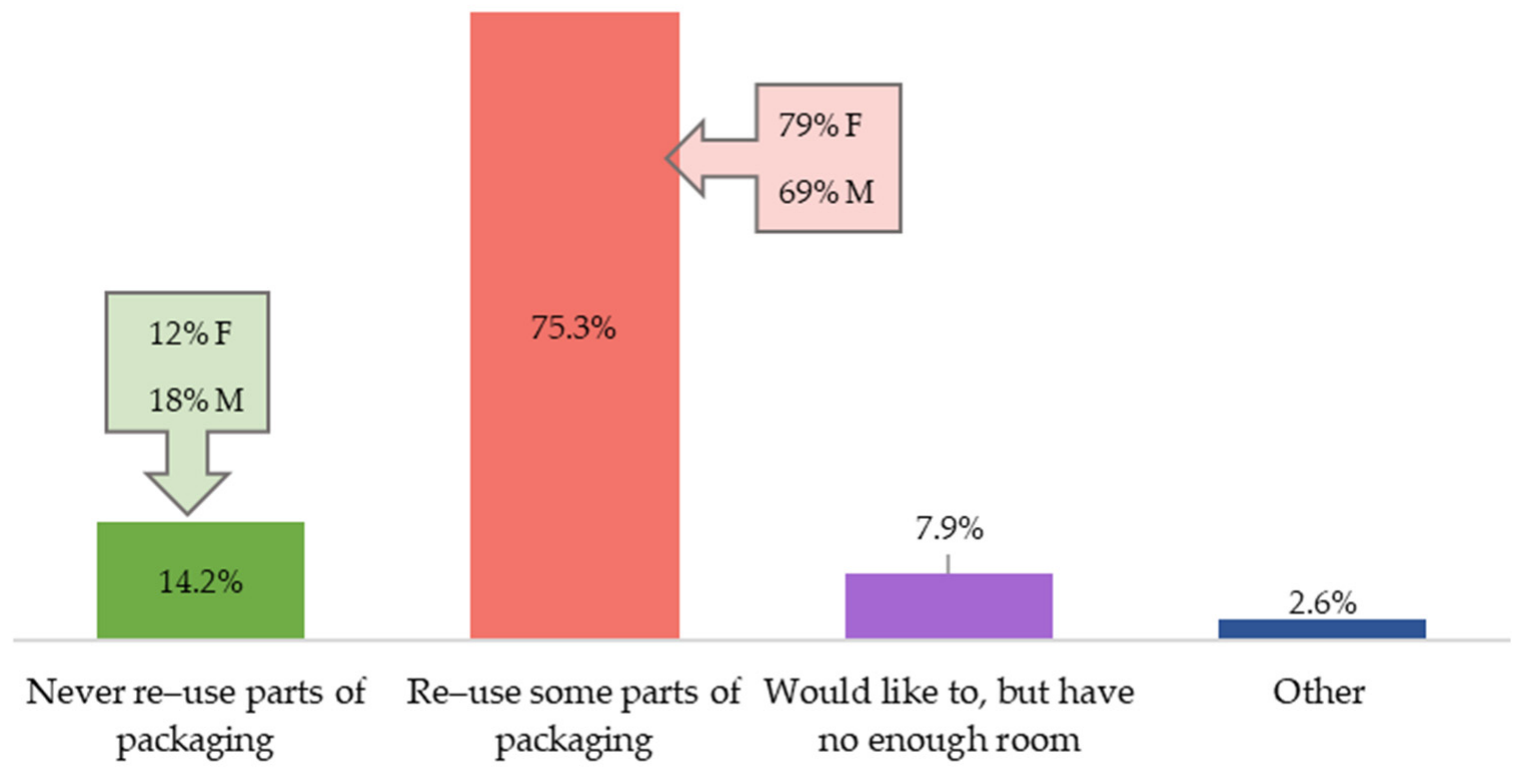

Figure 5. Reuse of some packaging parts and gender structure of relevant answers.

We examined the gender distribution inside the two categories that never reuse and always reuse part of the packaging, to individuate a possible gender dependency. The results are reported in Figure 5, highlighting some differences between gender percentages. Females' fraction is in fact higher than males' fraction among those who have the habit to reuse packaging parts (79\% female vs. $69 \%$ male), and lower in the case of no reuse (12\% female vs. $18 \%$ male), although both genders have nearly the same share in both categories (not shown in the figure).

As the next step, the two above-mentioned categories were also analysed in light of a scoring question where the participants were asked to rate their familiarity with the CE concept (see Q12, Table 1). The second column of the Table 2 reports the scores given by those who are used to reusing packaging parts, related to their knowledge about CE and the third one contains correspondingly the scores of those who never reuse. From Table 2, one can see that the average score in the case of being accustomed to reusing is higher than that of "not being". Low scores in familiarity with CE $(\leq 4)$ correspond to high possibility to "never reuse". The situation is reversed in the case of higher scores (first row). Thus, the two concepts of reuse and CE seem related: those who have great knowledge about CE are more prone to reuse than those who do not. To verify this hypothesis, an F-test (to determine the equality or inequality of the variances $(\sigma)$ of the two samples) was performed, followed by a T-test to determine if the mean values are equal or not. The F-test (see Table 2) showed the difference of variances, while the T-test (with unequal variance, see again Table 2 , last block) showed that the mean values $(\mu)$ are not equal 
(T-stat > T-Critical), confirming that the knowledge about CE affects performing (or not) reuse of packaging parts.

Table 2. Habit of reusing packaging parts and score to familiarity with circular economy.

\begin{tabular}{|c|c|c|}
\hline Scores to Familiarity with CE & Reuse Some Parts of Packaging & Never Reuse Parts of Packaging \\
\hline$\geq 8$ & $34 \%$ & $18 \%$ \\
\hline $5,6,7$ & $53 \%$ & $43 \%$ \\
\hline$\leq 4$ & $15 \%$ & $35 \%$ \\
\hline Not given & $2 \%$ & $4 \%$ \\
\hline Average score & 6.49 & 5.36 \\
\hline \multicolumn{3}{|c|}{ F-test $\left(\operatorname{Hyp} H_{0}: \sigma_{1}^{2}=\sigma_{2}^{2}\right)$} \\
\hline Variance & 4.17 & 5.41 \\
\hline Observations & 385 & 69 \\
\hline $\mathrm{df}$ & 384 & 68 \\
\hline $\mathrm{F}$ & \multicolumn{2}{|c|}{0.77} \\
\hline F Critical & \multicolumn{2}{|c|}{0.75} \\
\hline Result of the test & \multicolumn{2}{|c|}{ unequal variances } \\
\hline \multicolumn{3}{|c|}{$T$-test with equal variances $\left(H y p H_{0}: \mu_{1}=\mu_{2}\right)$} \\
\hline$\alpha$ (significance level) & \multicolumn{2}{|c|}{$5 \%$} \\
\hline $\mathrm{df}$ & \multicolumn{2}{|c|}{88} \\
\hline T Stat & \multicolumn{2}{|c|}{3.80} \\
\hline T Critical & \multicolumn{2}{|c|}{1.98} \\
\hline Result of the test & \multicolumn{2}{|c|}{ Rejection of $H_{0}$} \\
\hline
\end{tabular}

Another statistical analysis was performed to determine if there was a significant difference between the means of the scores males and females gave to their familiarity with CE within the two previously mentioned groups (see Table 3). As before, two Ftests were performed to check the equality or inequality of the variances of two subgroups. The analysis (shown in the second block of Table 3) rejected the equal variance hypothesis between the sub-groups of those who do reuse ( $\mathrm{F}<\mathrm{F}$ Critical) while confirming it (F > F Critical) in the case of "never reuse". The $t$-tests (see the two last blocks of the Table 3) showed no significant difference between mean scores between genders within the two groups: women and men who do not reuse have the same knowledge about $\mathrm{CE}$, and the same holds for women/men who reuse parts of packaging.

Table 3. $T$-test statistic between genders within the groups with the same "reuse" habit on the familiarity with circular economy concept.

\begin{tabular}{|c|c|c|c|c|}
\hline \multicolumn{5}{|c|}{$t$-Test; Scores to Familiarity with Circular Economy and Gender } \\
\hline & \multicolumn{2}{|c|}{ Reuse Some Parts of Packaging } & \multicolumn{2}{|c|}{ Never Reuse Parts of Packaging } \\
\hline & $\mathrm{F}$ & $\mathrm{M}$ & $\mathrm{F}$ & M \\
\hline Mean & 6.40 & 6.67 & 5.03 & 5.73 \\
\hline Variance & 3.88 & 4.67 & 4.99 & 5.77 \\
\hline \multicolumn{5}{|c|}{ F-test $\left(\operatorname{Hyp} H_{0}: \sigma_{1}^{2}=\sigma_{2}^{2}\right)$} \\
\hline$\alpha$ (significance level) & \multicolumn{2}{|c|}{$5 \%$} & \multicolumn{2}{|c|}{$5 \%$} \\
\hline observations & 246 & 139 & 36 & 39 \\
\hline df & 245 & 138 & 35 & 38 \\
\hline $\mathrm{F}$ & \multicolumn{2}{|c|}{0.83} & \multicolumn{2}{|c|}{1.15} \\
\hline F Critical & \multicolumn{2}{|c|}{0.78} & \multicolumn{2}{|c|}{1.77} \\
\hline Results of the test & \multicolumn{2}{|c|}{ Rejection of $H_{0}$} & \multicolumn{2}{|c|}{ Acceptance of $H_{0}$} \\
\hline
\end{tabular}


Table 3. Cont.

\begin{tabular}{ccc}
\hline & $\boldsymbol{t}$-Test; Scores to Familiarity with Circular Economy and Gender \\
\hline & Reuse Some Parts of Packaging & Never Reuse Parts of Packaging \\
\hline$\alpha$ (significance level) & T-test with unequal variance $\left(H y p H_{0}: \mu_{1}=\mu_{2}\right)$ & - \\
T Stat & $5 \%$ & - \\
T Critical & 1.25 & - \\
Result of the test & 1.99 & $5 \%$ \\
\hline & Acceptance of $H_{0}$ & 1.20 \\
\hline (significance level) & T-test with equal variance $\left(\right.$ Hyp $\left.H_{0}: \mu_{1}=\mu_{2}\right)$ & 1.97 \\
I T Stat I & - & Acceptance of $H_{0}$
\end{tabular}

One of the factors which could influence waste sorting is the accessibility to, and location of, the recycle bins, as also pointed out in [23]. This factor was investigated through a D question which asked the participants about the "availability of recycle bins in the proximity of their residence" (see Q28, Table 1). The answers included "always available and in my proximity", "I am obliged to keep some categories inside my dwelling and bring in for collection times", "available but often full", and "other" (Figure 6). Being among the last pages of the survey, this question had a greater number of not given answers (see Q28, Appendix B). Almost half of the answerers have regular access to recycle bins while around $30 \%$ of them find the bins capacity not sufficient, and $17 \%$ of participants have no access to recycle bins for some waste types. Amongst the answers in the other category, the most frequent were those who declared a door-to-door collection system, with their personal bins provided by the local Waste Management Authority. In the second position there were those who stated they have the bins in their own yard but they are shared with other neighbours. Just three cases, those who indicated not to sort waste, have mentioned that in their city/neighbourhood (they all belong to an urban context) the waste sorting system was not active at all.

The bins exist but are often full

I am obliged to keep some sorted waste at home and bring it out for the collecting time The bins are always available and are close to my home

Other

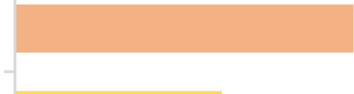

$28 \%$

\section{$17 \%$}
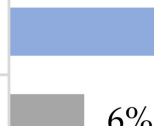

Figure 6. State of the recycle bins in the vicinity of the residence.

To find out the impact of residence context on availability of the bins, the above question was investigated more in detail based on the urban context (Q3, Table 1). Please note that the "other" and "not given" answers are not present in the statistics. People living in all considered residence contexts have a regular access to recycle bins with $40 \%$ of probability or more. Surprisingly, as it can be seen, the statistics related to the rural residents showed fewer issues related to recycling bins with respect to urban and pre-urban residents (Table 4). 
Table 4. Residence context percentage and state of recycle bins.

\begin{tabular}{cccc}
\hline \multicolumn{4}{c}{ Residence Context and State of the Recycle Bins } \\
\hline State of the Recycle Bins & Urban & Peri-Urban & Rural \\
\hline Always accessible and with sufficient capacity & $47 \%$ & $40 \%$ & $46 \%$ \\
Available but of insufficient capacity & $27 \%$ & $27 \%$ & $10 \%$ \\
Not available for all types of waste, need to bring & $27 \%$ & $27 \%$ & $10 \%$ \\
out the sorted waste for collection time & & \\
\hline
\end{tabular}

\subsection{Scoring Questions}

This section deals mainly with the results of the scoring questions, in some cases with a combination with other question categories, like the previous section.

To investigate a potential, reciprocate impact of the study level (Q4, Table 1) and familiarity with the reason of waste sorting (Q11, Table 1), these questions were analysed together. The answers to the question "study level" were "high school graduated or student", "professional school graduated or student", "university student or graduated", "PhD and higher", and "other". The first and second answers have been aggregated into a unique new category "diploma or school student".

As mentioned before and as can also be seen in Appendix B, Q11, the scores of less than 5 are just five cases. Thus, only high-frequency scores (from 5 on) are reported in Figure 7. Please note that the colours in each bar show the frequency of answerers with a certain study level, normalised with respect to the total numbers of the participants with the same study level. In other words, the colours show the percentage distribution of same study level in the different scores. As it can be seen, the frequency of all study levels increases, nearly with the same trend, increasing the scores from 5 to 10, and no particular difference could be seen between different study levels in the same score (especially for scores $\geq 8$ ). It can be concluded that no significant dependency exists between the study level and the knowledge about the importance of waste segregation.

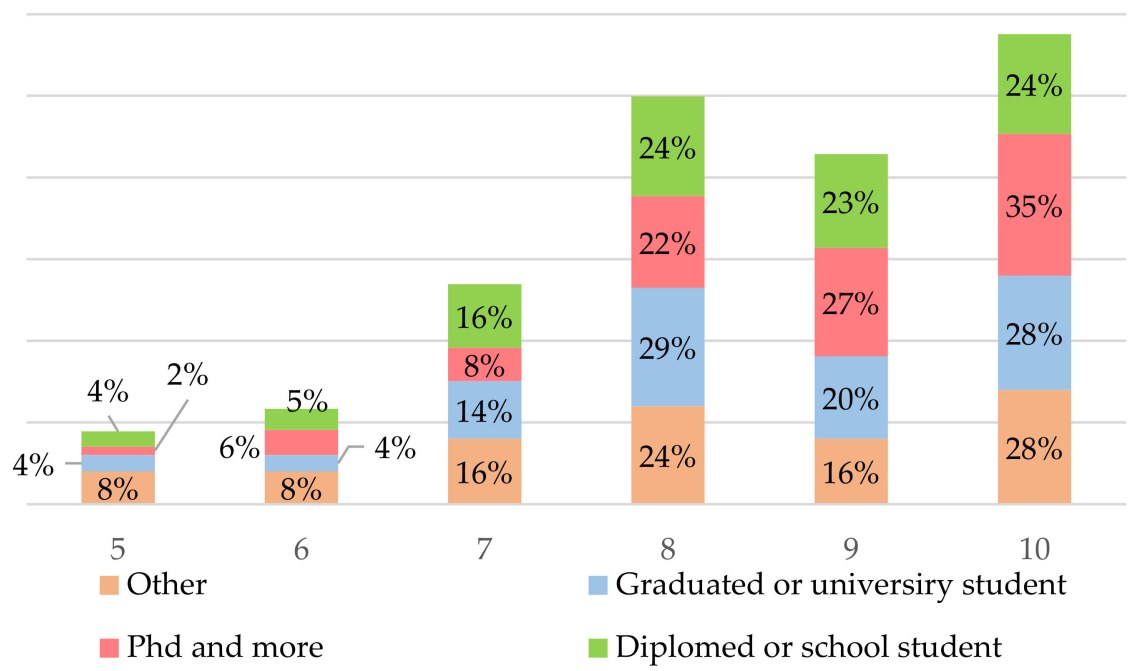

Figure 7. Distribution of different study levels within high frequency scores of "familiarity with the importance of waste recycling".

To study any differences between the mean values $\mu$ of the scores given to Q11 by people with different study levels $\left(H_{0}: \mu_{1}=\mu_{2}=\mu_{3}\right)$, a dedicated analysis of variance was performed. The choice of an ANOVA (and not a $t$-test) is driven by the fact that the comparison made here is between more than two groups (three study levels), while the $t$-test enables the comparison between two groups. The one-way ANOVA with a significance level $\alpha$ of $5 \%$ (see Table 5) did not show any difference between the mean 
values of the scores in different study levels ( $-\mathrm{F}$ Critical $<\mathrm{F}<\mathrm{F}$ Critical), confirming that no significant dependency between the study level and the knowledge about the importance of waste segregation exists.

Table 5. Results of one-way ANOVA on study level and knowing the reason of waste sorting and recycling. In the columns of the ANOVA analysis: SS is sum of squares, Df is degrees of freedom, the mean square MS is computed as SS/DF, and F is defined as MS (between groups)/MS (within groups).

\begin{tabular}{|c|c|c|c|c|c|c|}
\hline \multicolumn{2}{|c|}{ Groups } & \multicolumn{2}{|c|}{ Average } & \multicolumn{3}{|c|}{ Variance } \\
\hline \multicolumn{2}{|c|}{ School student/Diploma } & \multicolumn{2}{|c|}{8.26} & \multicolumn{3}{|c|}{2.31} \\
\hline University stud & graduated & \multicolumn{2}{|c|}{8.39} & \multicolumn{3}{|c|}{1.98} \\
\hline \multicolumn{2}{|c|}{ PhD and higher } & \multicolumn{2}{|c|}{8.69} & \multicolumn{3}{|c|}{1.72} \\
\hline \multicolumn{7}{|c|}{ ANOVA } \\
\hline $\begin{array}{l}\text { Source of } \\
\text { Variation }\end{array}$ & SS & Df & MS & $\mathrm{F}$ & $p$-value & F Crit \\
\hline $\begin{array}{l}\text { Between groups } \\
\text { Within group }\end{array}$ & $\begin{array}{c}6.90 \\
974.19\end{array}$ & $\begin{array}{c}2 \\
476\end{array}$ & $\begin{array}{l}3.45 \\
2.05\end{array}$ & 1.69 & 0.187 & 3.02 \\
\hline
\end{tabular}

In our everyday life, media are one of the most important ways to get information on different topics. The participants were asked to score the information conveyed by media about the correct methods of waste sorting (Q14, Table 1). Although the overall opinion is rather positive, it is not high: almost $60 \%$ of the answerers graded it with medium scores, i.e., 5-7 (see Figure 8). The remaining $40 \%$ are nearly equally distributed between the three upper and four lower scores. The variance of the answers in this case is 3.97 , and the average score is 5.89. This addresses the facts that media can still improve a lot in transmitting information relative to waste separation and recycling.

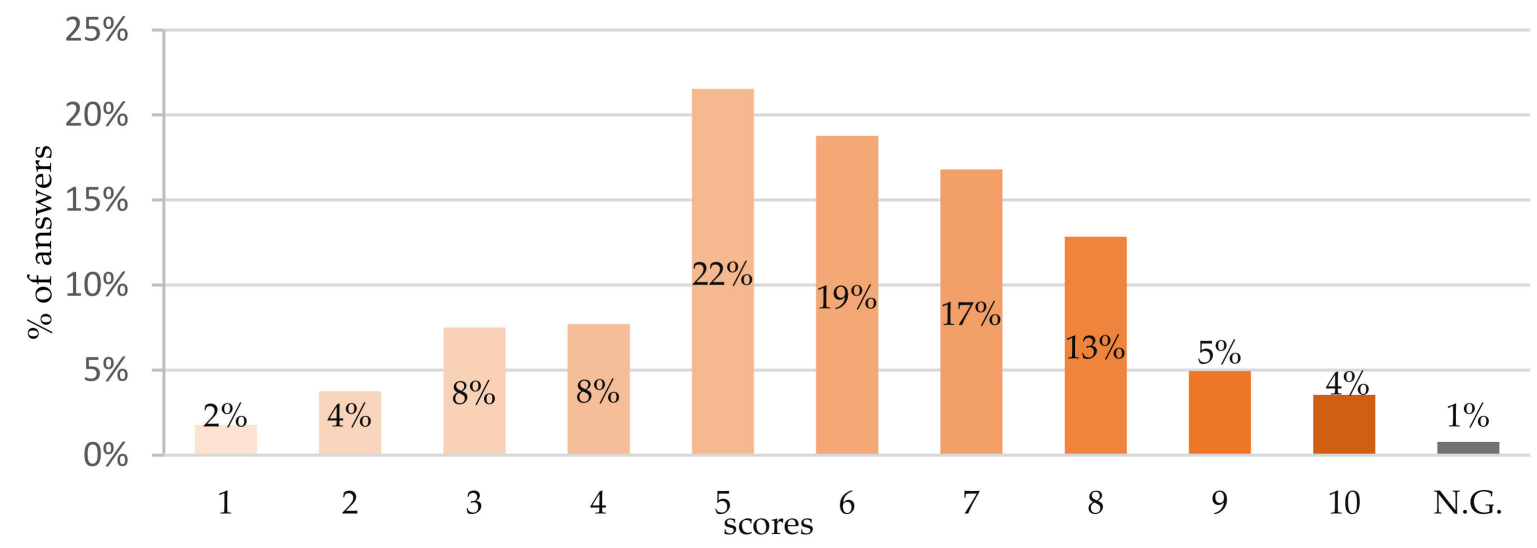

Figure 8. Scores given to information conveyed by media about correct differentiation of waste (N.G. indicates "Not Given").

In another scoring question, participants were asked to score the on-pack recycling indications of mono and multi-component packs (Q22 \& Q23, Table 1). As it was expected, single-component packs have greater satisfaction among the answerers (see Figure 9). The mode in case of multi-component packs was scored at 5, while it was at 7-8 in the case of single-component packs. Comparing the mean values of scores for both products confirms the higher satisfaction of the end users from the single-component recycling indications ( 6.89 vs. 5.43). To obtain a more quantitative tool to compare globally the answers given for the two different pack types, an ad-hoc weighted score (see Table 6) was introduced, multiplying each score by its frequency. The weighted scores, with mean values of the scores, also confirm the prevalence of quality of indications of single component packs. The variances of the two categories are rather similar. 


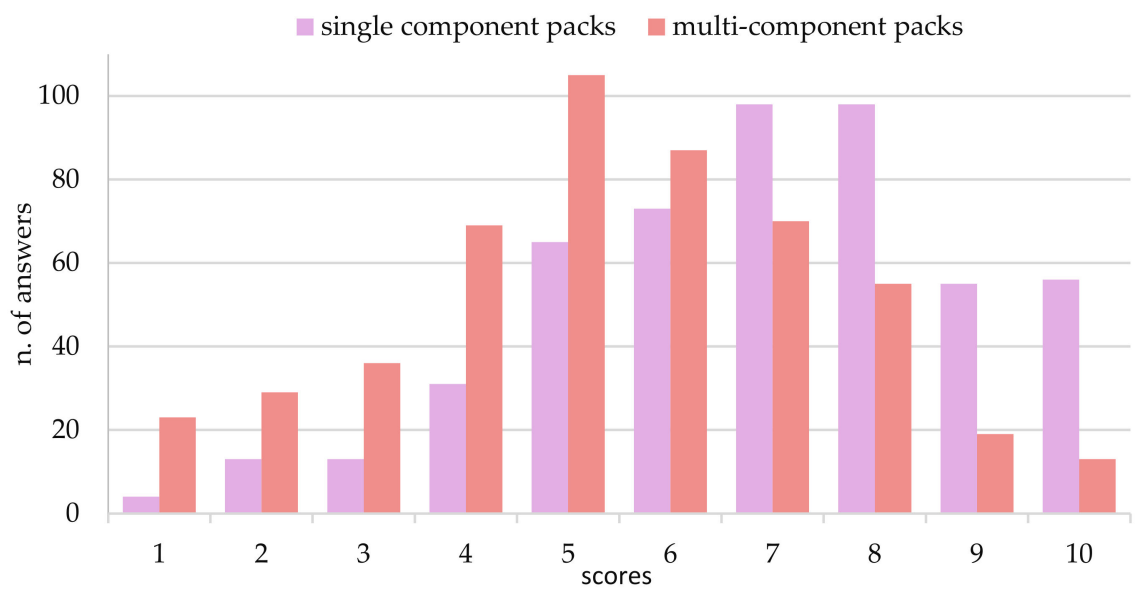

Figure 9. Comparison of the scores given to on-pack indications of single and multi-component packs.

Table 6. Weighted scores, means and variances of scores given to recycling indications of different products and packaging materials.

\begin{tabular}{cccc}
\hline Package or Product Type & Weighted Score & Mean & Var \\
\hline Single component & 3481 & 6.89 & 4.26 \\
Multi-component & 2743 & 5.43 & 4.44 \\
\hline Ready meals-presence of indications & 2624 & 5.30 & 4.70 \\
Ready meals-clarity of indications & 2531 & 5.23 & 4.31 \\
\hline Cosmetics-presence of indications & 2495 & 5.04 & 5.10 \\
Cosmetics-clarity of indications & 2451 & 5.06 & 4.74 \\
\hline Paper package & 3150 & 6.83 & 4.73 \\
Glass containers & 3079 & 6.70 & 5.25 \\
Plastic packs-not vacuum & 2759 & 5.97 & 5.04 \\
Metal packages & 2686 & 5.81 & 5.41 \\
Plastic packs-vacuum & 2539 & 5.49 & 5.75 \\
Wood packages & 2448 & 5.27 & 6.03 \\
\hline
\end{tabular}

As a result of the growing number of persons living alone, the increasing participation of females in different occupations, and changing lifestyle of families, the consumption of ready meals is increasing as well [43]. Thus, studying the recycling indication of such products seems appropriate. Both presence and clarity of the sorting indications (Q24 \& Q26, Table 1) for ready meals were investigated. The results (see Figure 10) show quite a similar distribution. Both sets of data have their mode at five with a larger tail towards lower scores (1-2). The mean values of the scores in both cases are also very close (5.30 vs. 5.23 , see Table 6) and show the similarity between the distribution of the answers relative to the existence and clarity of ready meal packages. Note, however, that some marginal bias of the scores 1 and 10 is also present.

Considering also the weighted scores, obtained as explained above (see Table 6), (2624 vs. 2531), both are relatively small (having very close average values), confirming that the presence and clarity of the recycling indications in case of ready meals require additional improvements.

The questions above were repeated for the cosmetics (Q25 \& Q27, Table 1) and the results are showed in Figure 11. In this case, both charts have their mode at 5 with the difference that clarity is more peaked than presence (which can be seen also in smaller variance for scores given to clarity (4.74) with respect to the presence's scores (5.10) reported in Table 6. Although the variance of clarity of indications showed a smaller value and thus less distributed scores, the mean values are very close (5.04 vs. 5.06$)$ and thus no significant prevalence of one factor with respect to the other is seen. Again, a bias for the lowest and 
highest scores is visible, and the scores 1-2 show a much higher frequency than the scores $9-10$. The weighted scores (see Table 6) are again fully comparable (2495 vs. 2451) and are even lower than in the case of the ready meals. This implies that the recycling indications of ready meals satisfy more the consumers than those of cosmetics.

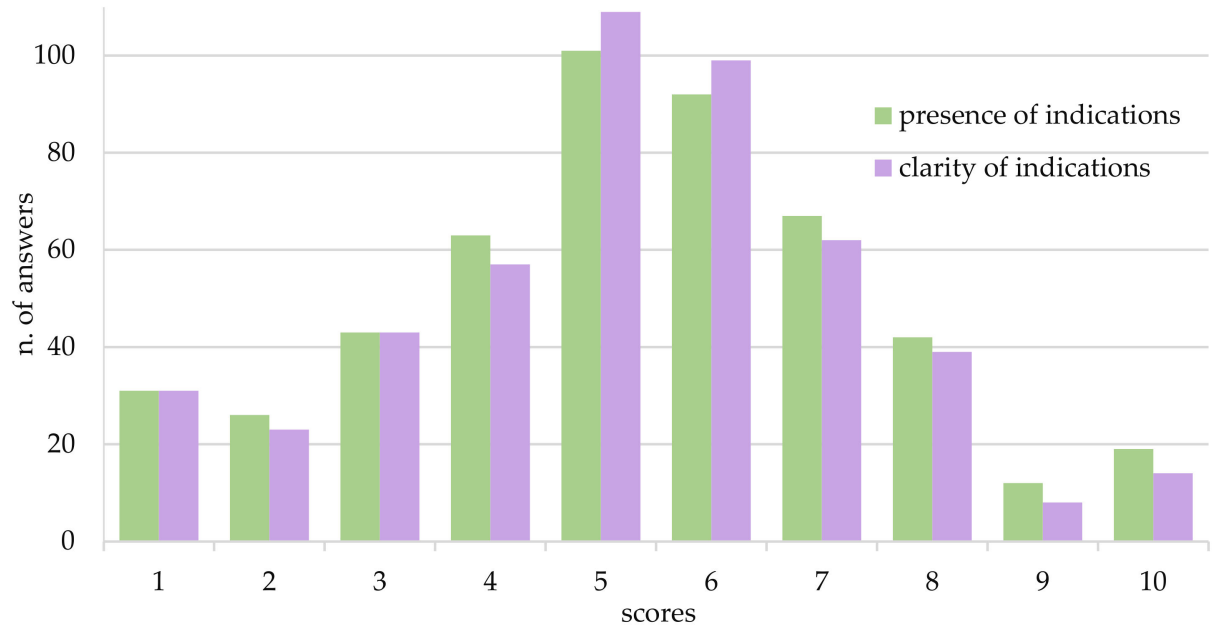

Figure 10. Comparison of the scores given to presence and clarity of on-pack recycling indications of ready meals.

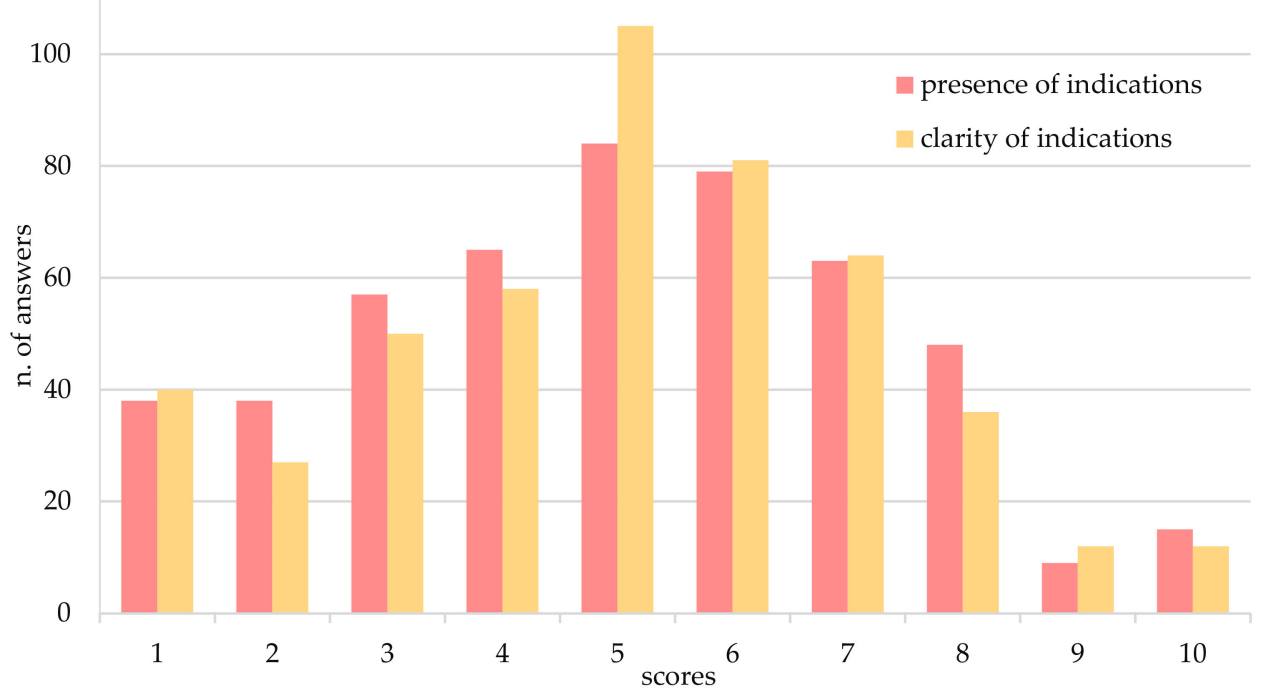

Figure 11. Comparison of the scores given to presence and clarity of on-pack indications of cosmetics.

Another set of $\mathbf{S}$ questions asked the participants to evaluate the on-pack recycling indications of packaging made of paper, plastic (vacuum and not), wood, tetra pack type, metal, and glass (Q15-Q21, Table 1). The modes (see Figure 12) in case of glass and paper are on 8 (left skewed), while it is on 6 in case of metal packing and both plastic packaging types, while wood and tetra pack have their mode on 5. The weighted scores change from 3150 in case of paper packs (and thus the highest satisfaction among packaging type indications) to 2437 for tetra pack package indications (see the last block of Table 6), corresponding to the least satisfaction of consumers. Looking at the variances of the scores, in case of paper packs, the smallest value (4.73) is found, implying that the scores of paper packs have a smaller spread pattern with respect to tetra packs which have the highest variance (6.03) and the lowest mean value of scores (5.27) among different package types. 


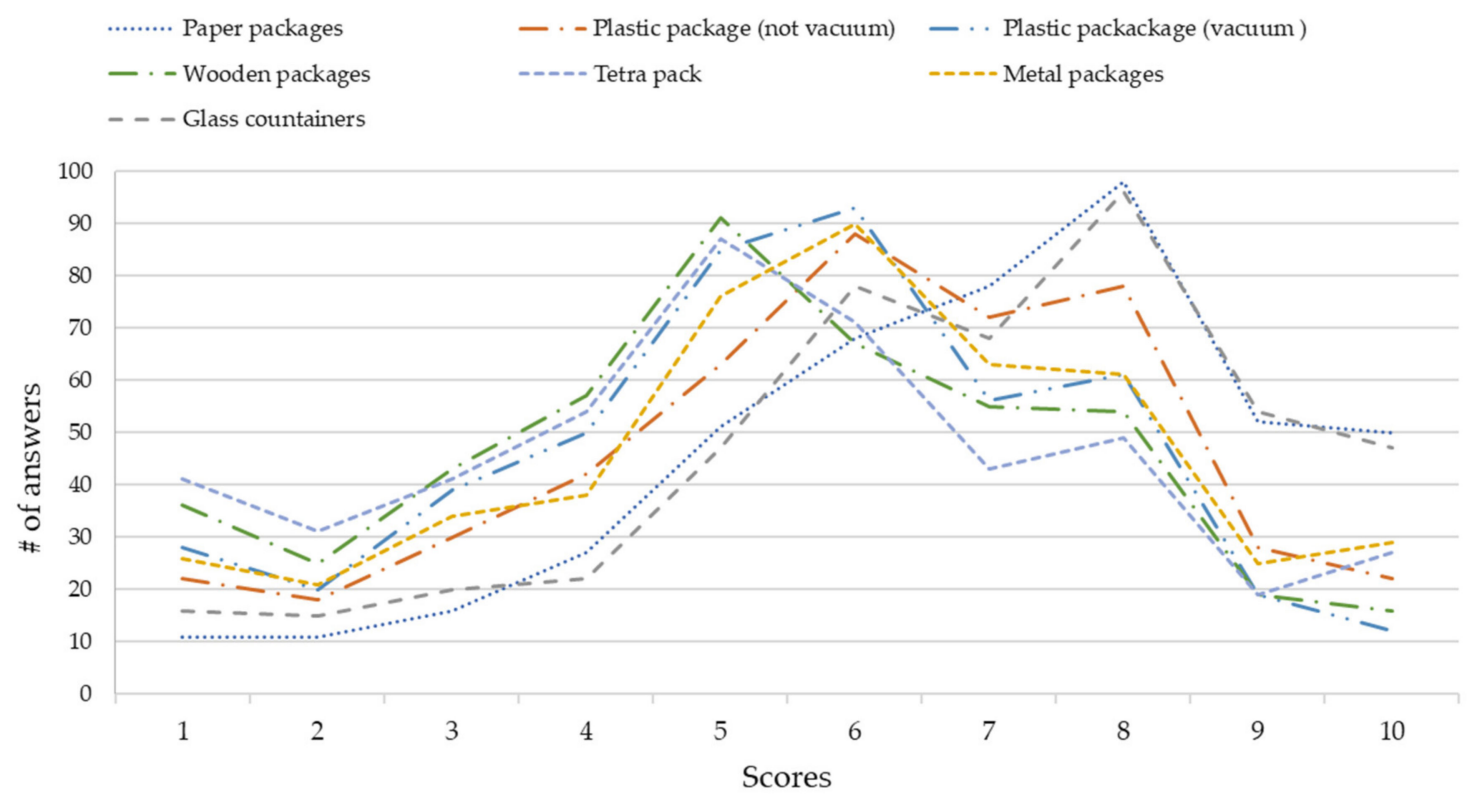

Figure 12. Comparison of the scores given to on-pack indications of different material package.

\section{Conclusions}

Waste sorting at the source, if performed inside dwellings and unlike methods applied in waste management facilities, requires no sophisticated machinery and manpower, and constitutes a very crucial step in MSW management. In this study, the main focus was examining the importance of the recycling habits inside our sample in relation to the quality of on-pack recycling labels, independently from other packaging factors, and analysing the impact of increasing their quality on waste segregation from the point of view of an Italian sample. Keeping in mind that obtaining a representative result for Italian society would require a bigger sample size and a more targeted and detailed survey, the study presented here was representative enough to identify the criticality of the on-pack recycling indications. According to the $70 \%$ of the participants and unlike the findings of Nemat et al. [22], on-pack indications are the main source of getting information on waste sorting pointing out that an easy-to-understand and clear on-pack labelling will improve drastically the result of the waste sorting.

One of the pillars of European waste hierarchy and sustainable waste treatment is waste reduction and reutilisation [7]. The survey showed that reutilisation of the useful packaging parts is common among three-quarters of the participants and dependes on their familiarity with circular economy. Moreover, a statistical analysis showed no significant difference between genders within the two groups of participants performing and not performing reuse of the packaging's parts.

According to the survey, the rural zone inhabitants perceive fewer issues with the availability or capacity of the recycle bins compared to the participants living in urban and pre-urban contexts.

Participants, independently from their study level, declare a high overall level of awareness about the importance of the recycling and waste differentiation $(90 \%$ of them have scored their knowledge about this topic with 7 or more, while the remaining $10 \%$ scored their knowledge from 3 to 6). A statistical analysis confirmed that there is no difference between participants with different study levels as far as their knowledge about the importance of performing recycling and waste sorting is concerned. The role of the media in conveying information relative to waste sorting is evaluated as medium-high but not satisfactory.

Multi-component packages are responsible for a big part of unrecycled packaging [13]. Comparison between the recycling indications of single- and multi-component packages 
showed a higher satisfaction in the case of single-component packages among the participants, confirming the results of Langley et al. [21].

The Presence and the clarity of an adequate on-pack recycling indication obtained a very similar score for both ready meals and cosmetics, both scored rather low and improvable. Ready meals obtained a higher overall score than cosmetics. The specific focus of scientists, packaging designers, and producers on recycling-related attributes of these families of products will improve the present indications and fill the potential gaps.

In the sorting of the on-pack recycling indications of different package materials, according to the participants ratings, paper-package indications rank first, followed by glass packages, plastic packages, metal packages, vacuum plastic packages, and wood. On-pack indications of tetra packs were evaluated to be the worst.

Comparing to the other characteristics of packaging (such as geometry, size, material, etc.) which impact end-users' recycling-related habits, provide packaging with a comprehensive and straight forward on-pack label is among the less infrastructure-requiring and less expensive solutions. Clearer on-pack recycling indications will reduce the confusion of the end-users, indicated to be among the major reasons of missorting of the waste [28], and increase the quality of waste sorting at the source. Thus, future studies which help to identify and improve the weaknesses of the recycling indications of packaging can improve of the efficiency of recycling behaviours of citizens and reduce waste production.

Author Contributions: Conceptualization, F.A.K. and L.S.; methodology, F.A.K.; software, F.A.K.; validation, F.A.K., L.S.; formal analysis, F.A.K.; investigation, F.A.K.; resources, L.S.; data curation, F.A.K.; writing—original draft preparation, F.A.K.; writing—review and editing, L.S.; visualization, F.A.K.; supervision, L.S.; project administration, F.A.K.; funding acquisition, L.S. Both authors have read and agreed to the published version of the manuscript.

Funding: This research received no external funding.

Institutional Review Board Statement: Not applicable.

Informed Consent Statement: Not applicable.

Data Availability Statement: Available on request.

Acknowledgments: The authors wish to thank all those who contributed to spreading the survey and enriching our data.

Conflicts of Interest: The authors declare no conflict of interest.

\section{Appendix A}

Here all the questions of the survey "Le abitudini dei cittadini riguardo la raccolta differenziata e l'effetto della chiarezza dell'etichettatura su di essa" are reported in the original language. For the questions marked with $\left({ }^{*}\right)$, the choice of only one answer was possible.

$$
\begin{aligned}
& \text { Q1: Età }\left(^{*}\right) \\
& \text { meno di } 15 \\
& \text { 15-30 } \\
& \bigcirc 31-45 \\
& \bigcirc 46-60 \\
& \bigcirc 61-75 \\
& \bigcirc \text { Piủ di } 76 \\
& \text { Q2: Sesso } \left.{ }^{*}\right) \\
& \bigcirc \text { Femmina } \\
& \text { Maschio }
\end{aligned}
$$


Q3: Città di residenza e contesto urbano in cui vivi (scegli una risposta e scrivi il nome della tua città) $\left({ }^{*}\right)$
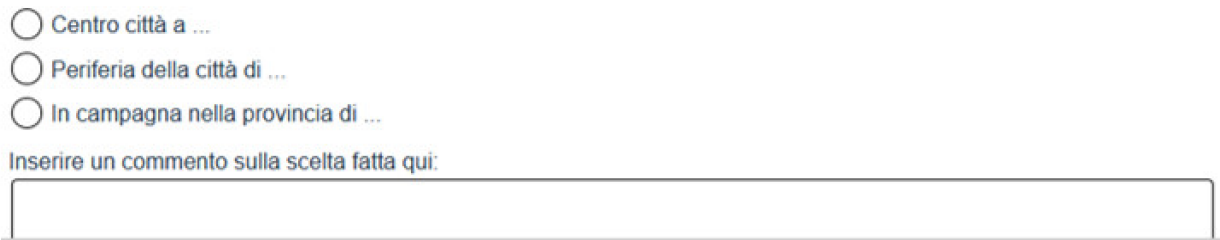

Q4: Titolo di studio conseguito (*)

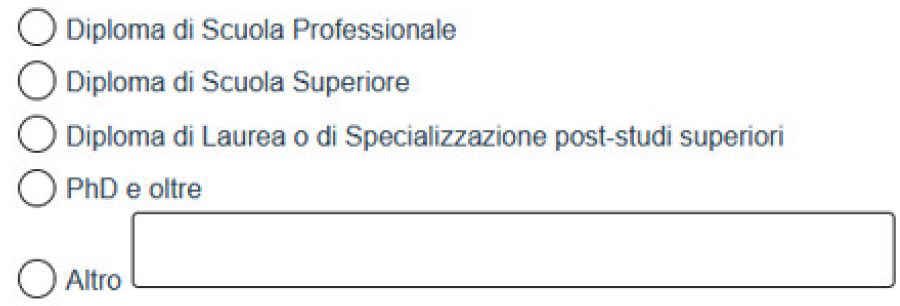

Q5: Stima la percentuale dei prodotti acquistati a casa tua in forma imballata e/o confezionata in plastica, polistirolo o cartone settimanalmente: $\left(^{*}\right)$
Meno di $25 \%$
Tra 26 e $50 \%$
Tra 51 e $75 \%$
Più di $76 \%$

Q6: Come descrivi la qualità dei rifiuti differenziati a casa tua? $\left(^{*}\right)$

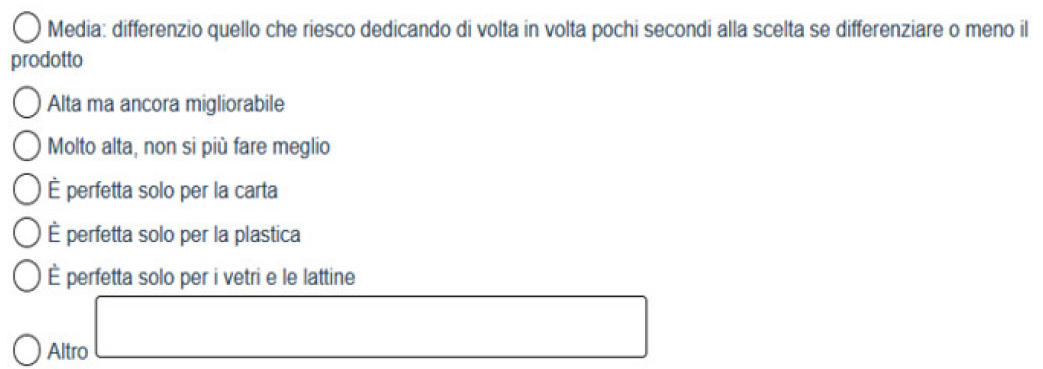

Q7: Qual è la ragione per cui non fai la raccolta differenziata? (appare solo se la risposta alla Q6 è non la faccio.)

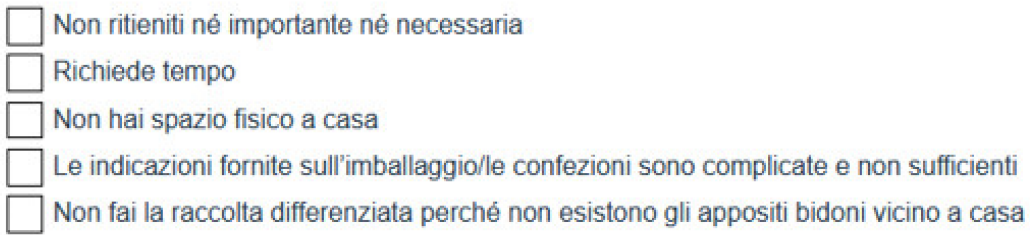

Q8: Una etichettatura chiara e semplice quanto influenza le tue abitudini a riguardo del riciclo dei rifiuti? $\left(^{*}\right)$ 
Può cambiarlo in modo decisivo perché questo è il problema

Non cambierà perché le etichette sono già sufficientemente chiare

Non cambierà perché non è questo il mio problema

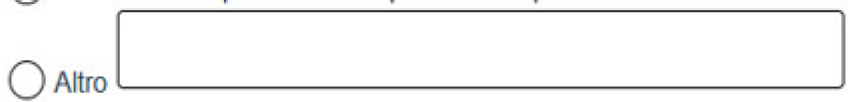

Q9: L'importanza che dai alla raccolta differenziata $\left(^{*}\right)$

$\bigcirc$ è molto importante, la faccio sempre e molto bene

$\bigcirc$ è importante, ma la faccio per alcune categorie (carta, plastica)

non lo faccio

Q10: Hai l'abitudine di riutilizzare alcuni pezzi delle confezioni (es: vassoi di plastica o carta, contenitori)? $\left(^{*}\right)$
$\bigcirc \mathrm{Si}$, tengo alcuni pezzi e li riutilizzo
Vorrei farlo, ma non posso perché non ho spazio
No, non faccio mai riutilizzo

Altro

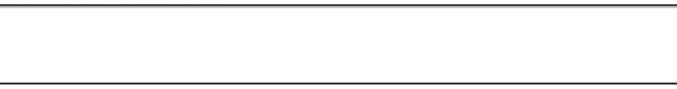

Q11-Q14: Che punteggio dai alle seguenti voci (1: pochissimo, 10: moltissimo)?

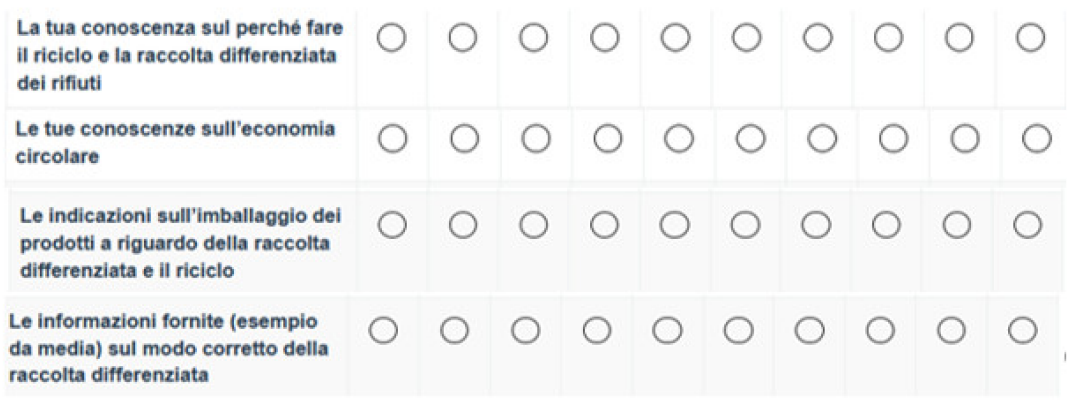

Q15-Q21: Dai un punteggio (1: pessimo, 10: ottimo) alle informazioni relative al reciclaggio/raccolta differenziata dei seguenti tipi di imballaggio:

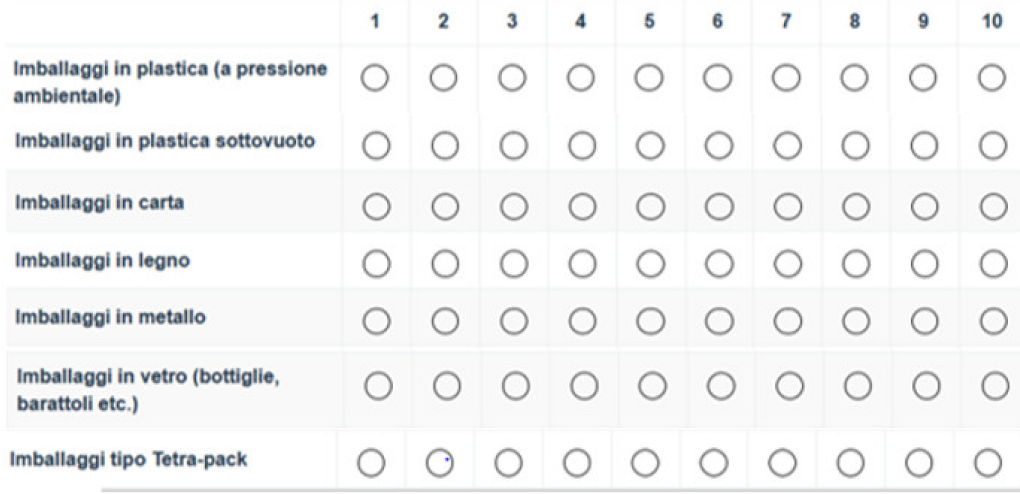

Q22-Q23: Dai un punteggio (1: pessimo, 10: ottimo) alle informazioni in generale sull'imballaggio/confezione di prodotti relativo a: 


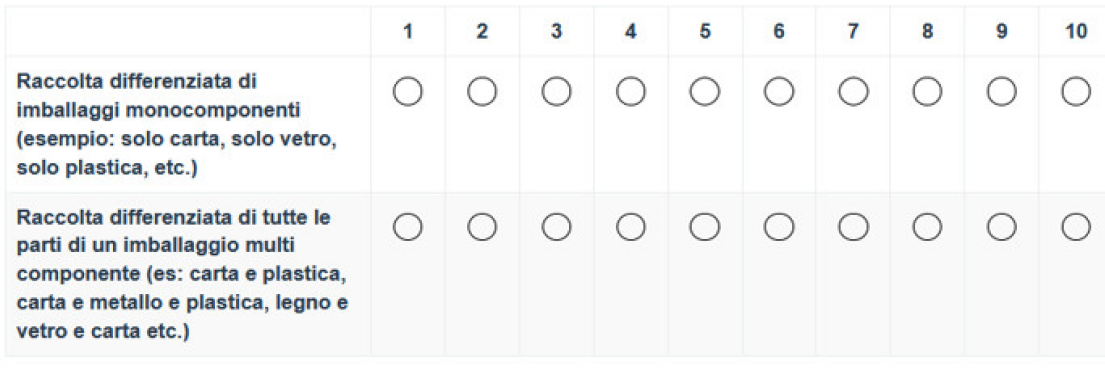

Q24-Q25: Dai un punteggio (1: pessimo, 10: ottimo) alla PRESENZA delle informazioni sull'imballaggio/confezione di prodotti relativo alla raccolta differenziata:

\begin{tabular}{l|ccccccccccc} 
& $\mathbf{1}$ & $\mathbf{2}$ & $\mathbf{3}$ & $\mathbf{4}$ & $\mathbf{5}$ & $\mathbf{6}$ & $\mathbf{7}$ & $\mathbf{8}$ & $\mathbf{9}$ & $\mathbf{1 0}$ \\
Piatti pronti & $\bigcirc$ & $\bigcirc$ & $\bigcirc$ & $\bigcirc$ & $\bigcirc$ & $\bigcirc$ & $\bigcirc$ & $\bigcirc$ & $\bigcirc$ & $\bigcirc$ \\
cosmetici & $\bigcirc$ & $\bigcirc$ & $\bigcirc$ & $\bigcirc$ & $\bigcirc$ & $\bigcirc$ & $\bigcirc$ & $\bigcirc$ & $\bigcirc$ & $\bigcirc$
\end{tabular}

Q26-Q27: Dai un punteggio (1: pessimo, 10: ottimo) alla CHIAREZZA delle informazioni sull'imballaggio/confezione di prodotti relativo alla raccolta differenziata

\begin{tabular}{l|c|c|c|c|c|c|c|c|c|c} 
& $\mathbf{1}$ & $\mathbf{2}$ & $\mathbf{3}$ & $\mathbf{4}$ & $\mathbf{5}$ & $\mathbf{6}$ & $\mathbf{7}$ & $\mathbf{8}$ & $\mathbf{9}$ & $\mathbf{1 0}$ \\
\hline Piatti pronti & $\bigcirc$ & $\bigcirc$ & $\bigcirc$ & $\bigcirc$ & $\bigcirc$ & $\bigcirc$ & $\bigcirc$ & $\bigcirc$ & $\bigcirc$ & $\bigcirc$ \\
cosmetici & $\bigcirc$ & $\bigcirc$ & $\bigcirc$ & $\bigcirc$ & $\bigcirc$ & $\bigcirc$ & $\bigcirc$ & $\bigcirc$ & $\bigcirc$ & $\bigcirc$
\end{tabular}

Q28: Come descrivi la disponibilità dei bidoni (per tutti i tipi di rifiuti) in prossimità della tua abitazione? $\left(^{*}\right)$

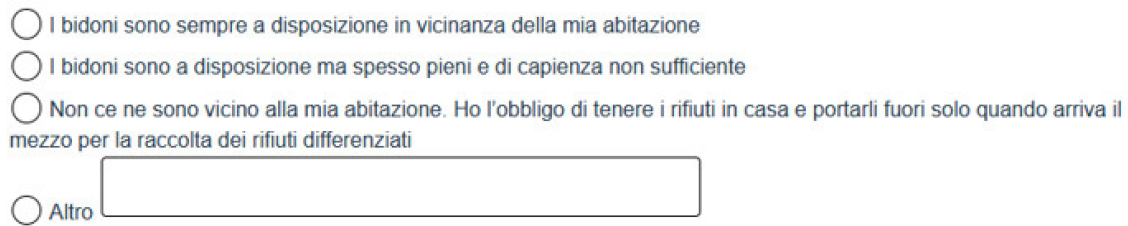

\section{Appendix B}

Table A1. Distribution of answers to (Q1 \& Q2).

\begin{tabular}{cccc}
\hline & \multicolumn{3}{c}{ Gender } \\
\hline Age & Total & F & M \\
\hline Less than 15 & 0 & 0 & 0 \\
$15-30$ & 129 & 61 & 68 \\
$31-45$ & 76 & 47 & 29 \\
$46-60$ & 138 & 101 & 37 \\
$61-75$ & 145 & 90 & 55 \\
76 and more & 18 & 8 & 10 \\
\hline
\end{tabular}


Table A2. Distribution of answers to (Q3).

\begin{tabular}{cc}
\hline Urban Context of Your Residence & $\boldsymbol{\#}^{\mathbf{1}}$ \\
\hline Urban & 286 \\
Peri-urban & 150 \\
Rural & 70 \\
\hline
\end{tabular}

${ }^{1}$ denotes the number of each answer.

Table A3. Distribution of answers to (Q4).

\begin{tabular}{cc}
\hline Study Level & $\#^{\mathbf{2}}$ \\
\hline Other & 25 \\
University student or graduated & 297 \\
Professional school student or Diploma & 20 \\
Graduate school student or Diploma & 115 \\
PhD and higher & 49 \\
\hline
\end{tabular}

2 denotes the number of each answer.

Table A4. Distribution of answers to (Q5).

\begin{tabular}{cc}
\hline Estimated Weekly Packed Products Consumption & $\#^{3}$ \\
\hline$<25 \%$ & 97 \\
$25-50 \%$ & 171 \\
$51-75 \%$ & 181 \\
$>76 \%$ & 57 \\
\hline
\end{tabular}

${ }^{3}$ denotes the number of each answer.

Table A5. Distribution of answers (Q6).

\begin{tabular}{cc}
\hline Quality of Your Sorted Waste & $\mathbf{A}^{\mathbf{4}}$ \\
\hline Very high, impossible to do better & 78 \\
High but improvable & 338 \\
Perfect just for paper & 3 \\
Perfect just for glass and cans & 5 \\
Perfect just for plastics & 0 \\
Medium, I do it as much as I can by spending a little time to sort & 61 \\
Other & 21 \\
\hline
\end{tabular}

${ }^{4}$ denotes the number of each answer.

Table A6. Distribution of answers (Q7). In case of choosing last option of Q9, this question appeared.

\begin{tabular}{cc}
\hline Why Don't You Do Waste Sorting? & $\#^{\mathbf{5}}$ \\
\hline You don't find in neither important not necessary & 0 \\
It is time consuming & 0 \\
You don't have enough room at home & 0 \\
The on-pack indications are complicated and insufficient & 0 \\
Because the differentiated bins are not at your home's proximity & 0 \\
\hline
\end{tabular}

5 denotes the number of each answer.

Table A7. Distribution of answers to (Q8).

\begin{tabular}{cc}
\hline Impact of a Clear and Simple on-Pack Labelling on Your Waste Sorting Result & $\#^{\mathbf{6}}$ \\
\hline Won't change, they are already clear enough & 53 \\
Won't change, this is not my problem & 48 \\
It would change it drastically because it is the problem & 373 \\
Other & 32 \\
\hline
\end{tabular}

\footnotetext{
${ }^{6}$ denotes the number of each answer.
} 
Table A8. Distribution of answers to (Q9).

\begin{tabular}{cc}
\hline The Importance You Give to Waste Sorting & $\#^{7}$ \\
\hline Find it important but do it for some categories & 86 \\
Find it crucial and do it as good as possible & 417 \\
I don't do it (conditional question) & 3 \\
\hline 7
\end{tabular}

${ }^{7}$ denotes the number of each answer.

Table A9. Distribution of answers to (Q10).

\begin{tabular}{cc}
\hline Do You Reuse Some Parts of Products' Packings & $\#^{8}$ \\
\hline Never & 72 \\
Yes, some parts & 381 \\
I would like to do it but have not enough room & 40 \\
Other & 13 \\
\hline
\end{tabular}

8 denotes the number of each answer.

Table A10. Distribution of answers to (Q11-Q14).

\begin{tabular}{|c|c|c|c|c|c|c|c|c|c|c|c|c|}
\hline & \multicolumn{12}{|c|}{ Scores } \\
\hline & 1 & 2 & 3 & 4 & 5 & 6 & 7 & 8 & 9 & 10 & N.G. & Mean \\
\hline Knowledge about why it is important to do recycling and waste sorting & 0 & 0 & 2 & 3 & 20 & 24 & 71 & 136 & 108 & 140 & 2 & 8.37 \\
\hline Knowledge about circular economy & 14 & 16 & 32 & 30 & 54 & 87 & 110 & 84 & 42 & 25 & 12 & 6.34 \\
\hline Quality of on-pack sorting and recycling indications & 12 & 17 & 28 & 47 & 94 & 103 & 88 & 55 & 22 & 29 & 11 & 5.97 \\
\hline Information conveyed by media about the correct ways of sorting the waste & 9 & 19 & 38 & 39 & 109 & 95 & 85 & 65 & 25 & 18 & 4 & 5.89 \\
\hline
\end{tabular}

Table A11. Distribution of answers to (Q15-Q21).

\begin{tabular}{|c|c|c|c|c|c|c|c|c|c|c|c|c|}
\hline & \multicolumn{12}{|c|}{ Scores } \\
\hline & 1 & 2 & 3 & 4 & 5 & 6 & 7 & 8 & 9 & 10 & N.G. & Mean \\
\hline On-pack sorting and recycling indications of Atmospheric Pressure Plastic packaging & 22 & 18 & 30 & 42 & 63 & 88 & 72 & 78 & 28 & 22 & 43 & 5.97 \\
\hline On-pack sorting and recycling indications of vacuum packaging & 28 & 20 & 39 & 50 & 85 & 93 & 56 & 61 & 19 & 12 & 43 & 5.49 \\
\hline On-pack sorting and recycling indications of paper packaging & 11 & 11 & 16 & 27 & 51 & 68 & 78 & 98 & 52 & 50 & 44 & 6.83 \\
\hline On-pack sorting and recycling indications of wood packaging & 36 & 25 & 43 & 57 & 91 & 67 & 55 & 54 & 19 & 16 & 43 & 5.29 \\
\hline On-pack sorting and recycling indications of metal packaging & 26 & 21 & 34 & 38 & 76 & 90 & 63 & 61 & 25 & 29 & 43 & 5.81 \\
\hline On-pack sorting and recycling indications of glass packaging & 16 & 15 & 20 & 22 & 47 & 78 & 68 & 96 & 54 & 47 & 43 & 6.70 \\
\hline On-pack sorting and recycling indications of tetra pack packaging & 41 & 31 & 41 & 54 & 87 & 71 & 43 & 49 & 19 & 27 & 43 & 5.27 \\
\hline
\end{tabular}

Table A12. Distribution of answers to (Q22 \& Q23).

\begin{tabular}{|c|c|c|c|c|c|c|c|c|c|c|c|c|}
\hline & \multicolumn{12}{|c|}{ Scores } \\
\hline & 1 & 2 & 3 & 4 & 5 & 6 & 7 & 8 & 9 & 10 & N.G. & Mean \\
\hline On-pack indications of single-component packaging & 4 & 13 & 13 & 31 & 65 & 73 & 98 & 98 & 55 & 56 & 0 & 6.89 \\
\hline On-pack indications of multi-component packaging & 23 & 29 & 36 & 69 & 105 & 87 & 70 & 55 & 19 & 13 & 0 & 5.43 \\
\hline
\end{tabular}

Table A13. Distribution of answers to (Q24-Q27).

\begin{tabular}{|c|c|c|c|c|c|c|c|c|c|c|c|c|}
\hline & \multicolumn{12}{|c|}{ Scores } \\
\hline & 1 & 2 & 3 & 4 & 5 & 6 & 7 & 8 & 9 & 10 & N.G. & Mean \\
\hline Presence of the on-pack recycling indications of Ready Meals & 31 & 26 & 43 & 63 & 101 & 92 & 67 & 42 & 12 & 19 & 10 & 5.30 \\
\hline Presence of the on-pack recycling indications of Cosmetics & 38 & 38 & 57 & 65 & 84 & 79 & 63 & 48 & 9 & 15 & 10 & 5.04 \\
\hline Clarity of the on-pack recycling indications of Ready Meals & 31 & 23 & 43 & 57 & 109 & 99 & 62 & 39 & 8 & 14 & 21 & 5.23 \\
\hline The clarity of the on-pack recycling indications of Cosmetics & 40 & 27 & 50 & 58 & 105 & 81 & 64 & 36 & 12 & 12 & 21 & 5.06 \\
\hline
\end{tabular}


Table A14. Distribution of answers to (Q28).

\begin{tabular}{cc}
\hline Availability of the Recycle Bins in the Proximity of Your Residence & $\# \mathbf{9}^{\mathbf{9}}$ \\
\hline The bins exist but are often full or with inadequate capacity & 126 \\
I am obliged to keep some sorted waste type at home and bring it out for the collection time & 77 \\
The bins are always available and are close to my home & 198 \\
Other & 56 \\
Not given & 49 \\
\hline
\end{tabular}

${ }^{9}$ denotes the number of each answer.

\section{References}

1. World Bank Trends in Solid Waste Management. Available online: https://datatopics.worldbank.org/what-a-waste/trends_in_ solid_waste_management.html (accessed on 7 July 2021).

2. Waste Management Market Size, Share and Growth Factors by 2027. Available online: https://www.alliedmarketresearch.com/ waste-management-market (accessed on 10 May 2021).

3. Mangarengi, N.A.P.; Zubair, A.; Abdurrahman, M.A. Analysis of infrastructure needs and operational systems for traditional market solid waste management (A case study on Makassar - Niaga Daya traditional market. IOP Conf. Series 2020, 1, 412. [CrossRef]

4. Wen, Z.; Xie, Y.; Chen, M.; Dinga, C.D. China's plastic import ban increases prospects of environmental impact mitigation of plastic waste trade flow worldwide. Nat. Commun. 2021, 12, 425. [CrossRef]

5. Chen, Y.; Cui, Z.; Cui, X.; Liu, W.; Wang, X.; Li, X.X.; Li, S. Life cycle assessment of end-of-life treatments of waste plastics in China. Resour. Conserv. Recycl. 2019, 146, 348-357. [CrossRef]

6. Eurostat Recycling-Secondary Material Price Indicator-Statistics Explained. Available online: https://ec.europa. eu/eurostat/statistics-explained /index.php?title=Recycling_--_secondary_material_price_indicator\#General_overview (accessed on 18 May 2021).

7. European Commission Waste Prevention and Management—Environment—European Commission. Available online: https: / / ec.europa.eu/environment/green-growth/waste-prevention-and-management/index_en.htm (accessed on 14 May 2021).

8. Eurostat Municipal Waste Statistics—Statistics Explained. Available online: https://ec.europa.eu/eurostat/statistics-explained/ index.php?title=Municipal_waste_statistics\#Municipal_waste_generation (accessed on 24 May 2021).

9. European Commission Consolidated Version of 94/62/EC Directive on Packaging and Packaging Waste; UR-Lex-01994L006220180704. Available online: https://eur-lex.europa.eu/legal-content/EN/TXT/?uri=CELEX\%3A01994L0062-20180704 (accessed on 18 May 2021).

10. EUROPEAN COMMISSION New Circular Economy Action Plan -EUR-Lex 52020DC0098 2020. Available online: https:/ / eur-lex. europa.eu/legal-content/EN/TXT/?qid=1583933814386\&uri=COM:2020:98:FIN (accessed on 14 May 2021).

11. European Commission Waste Framework Directive. Available online: https://ec.europa.eu/environment/topics/waste-andrecycling/waste-framework-directive_en (accessed on 14 May 2021).

12. Feber, D.; Nordigården, D.; Granskog, A.; Ponkshe, S.; Berg, P. The Drive toward Sustainability in Packaging-beyond the Quick Wins Can System-Level Approaches, Including Collaboration along the Value Chain, Make Our Approach to Packaging More Sustainable? 2020. Available online: https://www.asiascot.com/news/2020/05/15/the-drive-toward-sustainability-inpackaging-beyond-the-quick-wins / (accessed on 14 May 2021).

13. WRAP-A Guide to Evolving Packaging Design; Banbury, UK, 2007. Available online: https://www.proseworks.co.uk/ Downloads/Wrap-design-guidance.pdf (accessed on 24 September 2021).

14. Farmer, N. Trends in Packaging of Food, Beverages and Other Fast-Moving Consumer Goods (FMCG)—Markets, Materials and Technologies_Knovel; Woodhead Publishing: Sawston, UK, 2013; ISBN 978-0-85709-503-9.

15. Lindh, H.; Olsson, A.; Williams, H. Consumer Perceptions of Food Packaging: Contributing to or Counteracting Environmentally Sustainable Development? Packag. Technol. Sci. 2016, 29, 3-23. [CrossRef]

16. Nemat, B.; Razzaghi, M.; Bolton, K.; Rousta, K. The role of food packaging design in consumer recycling behavior-a literature review. Sustainability 2019, 11, 4350. [CrossRef]

17. Teisl, M.F.; Roe, B.; Hicks, R.L. Can Eco-Labels Tune a Market? Evidence from Dolphin-Safe Labeling. J. Environ. Econ. Manag. 2002, 43, 339-359. [CrossRef]

18. Bjørner, T.B.; Hansen, L.G.; Russell, C.S. Environmental labeling and consumers' choice-an empirical analysis of the effect of the Nordic Swan. J. Environ. Econ. Manag. 2004, 47, 411-434. [CrossRef]

19. Emblem, A. Packaging functions, chapter 3. In Packaging Technology Fundamentals, Materials and Processes; Woodhead Publishing: Sawston, UK, 2012; pp. 24-49.

20. Marsh, B.Y.K.; Bugusu, B. Food Packaging and Its Environmental Impact; Institute of Food Technologists, Washington, DC, USA, 2017. Available online: https://www.ift.org/news-and-publications/food-technology-magazine/issues/2007/april/features / food-packaging-and-its-environmental-impact (accessed on 14 May 2021).

21. Langley, J.; Turner, N.; Yoxall, A. Attributes of packaging and influences on waste. Packag. Technol. Sci. 2011, 24, 161-175. [CrossRef] 
22. Nemat, B.; Razzaghi, M.; Bolton, K.; Rousta, K. The potential of food packaging attributes to influence consumers' decisions to sort waste. Sustainability 2020, 12, 2234. [CrossRef]

23. Westerman, S.J.; Sutherland, E.J.; Gardner, P.H.; Baig, N.; Critchley, C.; Hickey, C.; Mehigan, S.; Solway, A.; Zervos, Z. The design of consumer packaging: Effects of manipulations of shape, orientation, and alignment of graphical forms on consumers' assessments. Food Qual. Prefer. 2013, 27, 8-17. [CrossRef]

24. Schoormans, J.; van den Berge, M.E.; van der Laar, G.; van den Berg-Weitzel, L. Designing packages that communicate product attributes and brand values: An exploratory method. Des. J. 2010, 13, 31-47. [CrossRef]

25. Ryynänen, T.; Rusko, E. Professionals' View of Consumers' Packaging Interactions-A Narrative Analysis. Packag. Technol. Sci. 2015, 28, 341-355. [CrossRef]

26. Plumb, A.; Downing, P.; Parry, A. Consumer Attitudes to Food Waste and Food Packaging. 2013, pp. 1-75. Available online: https:/ / wrap.org.uk/resources/report/consumer-attitudes-food-waste-and-food-packaging (accessed on 14 May 2021).

27. Williams, H.; Wikström, F.; Wetter-Edman, K.; Kristensson, P. Decisions on recycling or waste: How packaging functions affect the fate of used packaging in selected Swedish households. Sustainability 2018, 10, 4794. [CrossRef]

28. Wikström, F.; Williams, H.; Venkatesh, G. The influence of packaging attributes on recycling and food waste behaviour-An environmental comparison of two packaging alternatives. J. Clean. Prod. 2016, 137, 895-902. [CrossRef]

29. Rousta, K.; Dahlén, L. Source Separation of Household Waste Materials. In Resource Recovery to Approach Zero Municipal Waste; CRC Press: Boca Raton, FL, USA; Taylor \& Francis Group: Boca Raton, FL, USA, 2015; pp. 61-76.

30. Buelow, S.; Lewis, H.; Sonneveld, K. The role of labels in directing consumer packaging waste. Manag. Environ. Qual. An Int. J. 2010, 21, 198-213. [CrossRef]

31. Becker, M.W.; Sundar, R.P.; Bello, N.; Alzahabi, R.; Weatherspoon, L.; Bix, L. Assessing attentional prioritization of front-of-pack nutrition labels using change detection. Appl. Ergon. 2016, 54, 90-99. [CrossRef]

32. Santos, O.; Alarcão, V.; Feteira-Santos, R.; Fernandes, J.; Virgolino, A.; Sena, C.; Vieira, C.P.; Gregório, M.J.; Nogueira, P.; Graça, P.; et al. Impact of different front-of-pack nutrition labels on online food choices. Appetite 2020, 154, 104795. [CrossRef]

33. Thiene, M.; Scarpa, R.; Longo, A.; Hutchinson, W.G. Types of front of pack food labels: Do obese consumers care? Evidence from Northern Ireland. Food Policy 2018, 80, 84-102. [CrossRef]

34. Wikström, F.; Williams, H.; Verghese, K.; Clune, S. The influence of packaging attributes on consumer behaviour in food-packaging life cycle assessment studies-A neglected topic. J. Clean. Prod. 2014, 73, 100-108. [CrossRef]

35. Dectero Rifiuti- D.Lgs. 116/2020 del 3 Settembre 2020. Available online: https://www.gazzettaufficiale.it/eli/id/2020/09/11/2 0G00135/sg (accessed on 18 May 2021).

36. Decreto Legislativo 5 Febbraio 1997 Sugli Imballaggi e sui Rifiuti di Imballaggio- Dlgs 22/97. Available online: https://www. camera.it/parlam/leggi/deleghe/97022dl.htm (accessed on 18 May 2021).

37. Lanz, A.M.; Santini, A.F.; Adella, L.; Aragona, G.; Ermili, S.; Frittelloni, V.; Lupica, I.; Minniti, F. Rapporto Rifiuti UrbaniISPRA, 313/2019; ISPRA Istituto Superiore per la Protezione e la Ricerca Ambientale, Roma, Italy, 2019. Available online: http:/ / www.unirima.it/2020/12/17/ rapporto-rifiuti-urbani-ispra-edizione-2020/ (accessed on 18 May 2021).

38. APIC Associazione Portatori Impianto Cocleare. Available online: http:/ / www.apic.torino.it/ (accessed on 13 May 2021).

39. FIAB Torino Bici \& Dintorni. Available online: https:/ / www.biciedintorni.it/ (accessed on 13 May 2021).

40. Civancik-Uslu, D.; Puig, R.; Voigt, S.; Walter, D.; Fullana-i-Palmer, P. Improving the production chain with LCA and eco-design: Application to cosmetic packaging. Resour. Conserv. Recycl. 2019, 151, 104475. [CrossRef]

41. Bord, R.J.; O'Connor, R.E. The Gender Gap in Environmental Attitudes: The Case of Perceived Vulnerability to Risk. Soc. Sci. Q. 1997, 78, 830-840.

42. Trifuoggi, M.; Pagano, G.; Oral, R.; Gravina, M.; Toscanesi, M.; Mozzillo, M.; Siciliano, A.; Burić, P.; Lyons, D.M.; Palumbo, A.; et al. Topsoil and urban dust pollution and toxicity in Taranto (southern Italy) industrial area and in a residential district. Environ. Monit. Assess. 2019, 191, 1-12. [CrossRef] [PubMed]

43. Geeroms, N.; Verbeke, W.; Van Kenhove, P. Consumers' health-related motive orientations and ready meal consumption behaviour. Appetite 2008, 51, 704-712. [CrossRef] [PubMed] 